\title{
Bone-Targeting Prodrug Mesoporous Silica-Based Nanoreactor with Reactive Oxygen Species Burst for Enhanced Chemotherapy
}

\author{
Citation for published version (APA): \\ Tong, F., Ye, Y., Chen, B., Gao, J., Liu, L., Ou, J., van Hest, J. C. M., Liu, S., Peng, F., \& Tu, Y. (2020). Bone- \\ Targeting Prodrug Mesoporous Silica-Based Nanoreactor with Reactive Oxygen Species Burst for Enhanced \\ Chemotherapy. ACS Applied Materials \& Interfaces, 12(31), 34630-34642. \\ https://doi.org/10.1021/acsami.0c08992
}

\section{Document license: \\ TAVERNE}

DOI:

10.1021/acsami.0c08992

Document status and date:

Published: 05/08/2020

\section{Document Version:}

Publisher's PDF, also known as Version of Record (includes final page, issue and volume numbers)

\section{Please check the document version of this publication:}

- A submitted manuscript is the version of the article upon submission and before peer-review. There can be important differences between the submitted version and the official published version of record. People interested in the research are advised to contact the author for the final version of the publication, or visit the $\mathrm{DOI}$ to the publisher's website.

- The final author version and the galley proof are versions of the publication after peer review.

- The final published version features the final layout of the paper including the volume, issue and page numbers.

Link to publication

\footnotetext{
General rights

- You may freely distribute the URL identifying the publication in the public portal. follow below link for the End User Agreement:

www.tue.nl/taverne

\section{Take down policy}

If you believe that this document breaches copyright please contact us at:

openaccess@tue.nl

providing details and we will investigate your claim.
}

Copyright and moral rights for the publications made accessible in the public portal are retained by the authors and/or other copyright owners and it is a condition of accessing publications that users recognise and abide by the legal requirements associated with these rights.

- Users may download and print one copy of any publication from the public portal for the purpose of private study or research.

- You may not further distribute the material or use it for any profit-making activity or commercial gain

If the publication is distributed under the terms of Article 25fa of the Dutch Copyright Act, indicated by the "Taverne" license above, please 


\section{Bone-Targeting Prodrug Mesoporous Silica-Based Nanoreactor with Reactive Oxygen Species Burst for Enhanced Chemotherapy}

Fei Tong, Yicheng Ye, Bin Chen, Junbin Gao, Lu Liu, Juanfeng Ou, Jan C. M. van Hest, Shuwen Liu,* Fei Peng, ${ }^{*}$ and Yingfeng $\mathrm{Tu}^{*}$

Cite This: ACS Appl. Mater. Interfaces 2020, 12, 34630-34642

Read Online

\section{ACCESS | Lill Metrics \& More | 回 Article Recommendations | sl Supporting Information}

ABSTRACT: Cancer remains a primary threat to human lives. Recently, amplification of tumor-associated reactive oxygen species (ROS) has been used as a boosting strategy to improve tumor therapy. Here, we report on a bone-targeting prodrug mesoporous silica-based nanoreactor for combined photodynamic therapy (PDT) and enhanced chemotherapy for osteosarcoma. Because of surface modification of a bone-targeting biphosphate moiety and the enhanced permeability and retention effect, the formed nanoreactor shows efficient accumulation in osteosarcoma and exhibits long-term retention in the tumor microenvironment. Upon laser irradiation, the loaded photosensitizer chlorin e6 (Ce6) produces in situ ROS, which not only works for PDT but also functions as a trigger for controlled release of doxorubicin

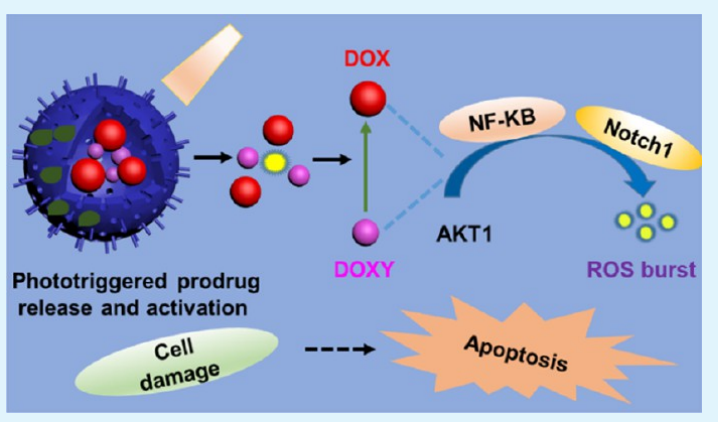
(DOX) and doxycycline (DOXY) from the prodrugs based on a thioketal (TK) linkage. The released DOXY further promotes ROS production, thus perpetuating subsequent DOX/DOXY release and ROS burst. The ROS amplification induces long-term high oxidative stress, which increases the sensitivity of the osteosarcoma to chemotherapy, therefore resulting in enhanced tumor cell inhibition and apoptosis. The as-developed nanoreactor with combined PDT and enhanced chemotherapy based on ROS amplification shows significant promise as a potential platform for cancer treatment.

KEYWORDS: ROS-sensitive nanoparticle, photodynamic therapy, chemotherapy sensitivity, ROS waterfall flow, osteosarcoma therapy

\section{INTRODUCTION}

Malignant tumors pose a serious threat to human health as millions of cancer patients have been suffering from related pain every year. ${ }^{1-3}$ As a cancerous bone tumor that usually develops in teenagers, osteosarcoma is a malignant connective tissue tumor in which tumor cells can directly produce bone and osteoid tissue. The malignancy of these tumors is very high and the prognosis is poor, resulting in a serious threat to the lives of teenagers. ${ }^{4}$ How to improve the therapeutic efficacy against osteosarcoma is one of the major challenges faced by researchers and clinicians. As a traditional approach, chemotherapy remains one of the main treatments for osteosarcoma at the present time. However, chemotherapeutic drugs based on small molecules are commonly associated with serious side effects, which limit their clinical applications. ${ }^{5-9}$ Therefore, development of novel drug delivery systems that can decrease adverse effects while improving therapeutic efficacy is vitally important for successful tumor therapy. ${ }^{10}$

As a well-established noninvasive technique, photodynamic therapy (PDT) involving light, photosensitizers, and molecular oxygen has been developed to generate in situ reactive oxygen species (ROS) for the treatment of various tumors, which displays significant therapeutic potential. ${ }^{11,12}$ The photosensitizer absorbs energy from photons and jumps to its excited state, followed by a transfer of energy from the excited photosensitizer to oxygen. The produced ROS results in an accumulation of oxidative stress that eventually exceeds a certain threshold and induces cell apoptosis by damaging cellular lipids, proteins, and DNA. ${ }^{13-22}$ However, there are restrictions on the utilization of photosensitizers because of the hydrophobicity, short half-life, and low tumor-targeting ability. ${ }^{23}$ Moreover, single PDT has a low selectivity in tumor tissues (only a few subtleties), which leads to a small scope and also limited application potential. Therefore, nano-based drug delivery systems loaded with photosensitizers and antitumor drugs synchronously for synergistic anticancer therapy should hold much promise. ${ }^{24,25}$

Herein, we develop a ROS-responsive prodrug mesoporous silica nanoreactor with bone-targeting property and PDTinduced ROS burst for enhanced chemodynamic therapy of osteosarcoma. Clinically, doxorubicin (DOX) is usually used

Received: May 16, 2020

Accepted: July 8, 2020

Published: July 8, 2020 
Scheme 1. Schematic Illustration of Ce6@ZA/MSN/DOX-TK-DOXY for Combined PDT and Enhanced Chemotherapy of Osteosarcoma; (A) Formation of Ce6@ZA/MSN/DOX-TK-DOXY; the Prodrug DOX-TK-DOXY was Loaded Into the MSN and Bone-Targeting Moiety ZA was Then Attached, Followed by the Surface Adsorpsion of Photosensitizer Ce6; (B) Intracellular Mechanism of Ce6@ZA/MSN/DOX-TK-DOXY ${ }^{a}$
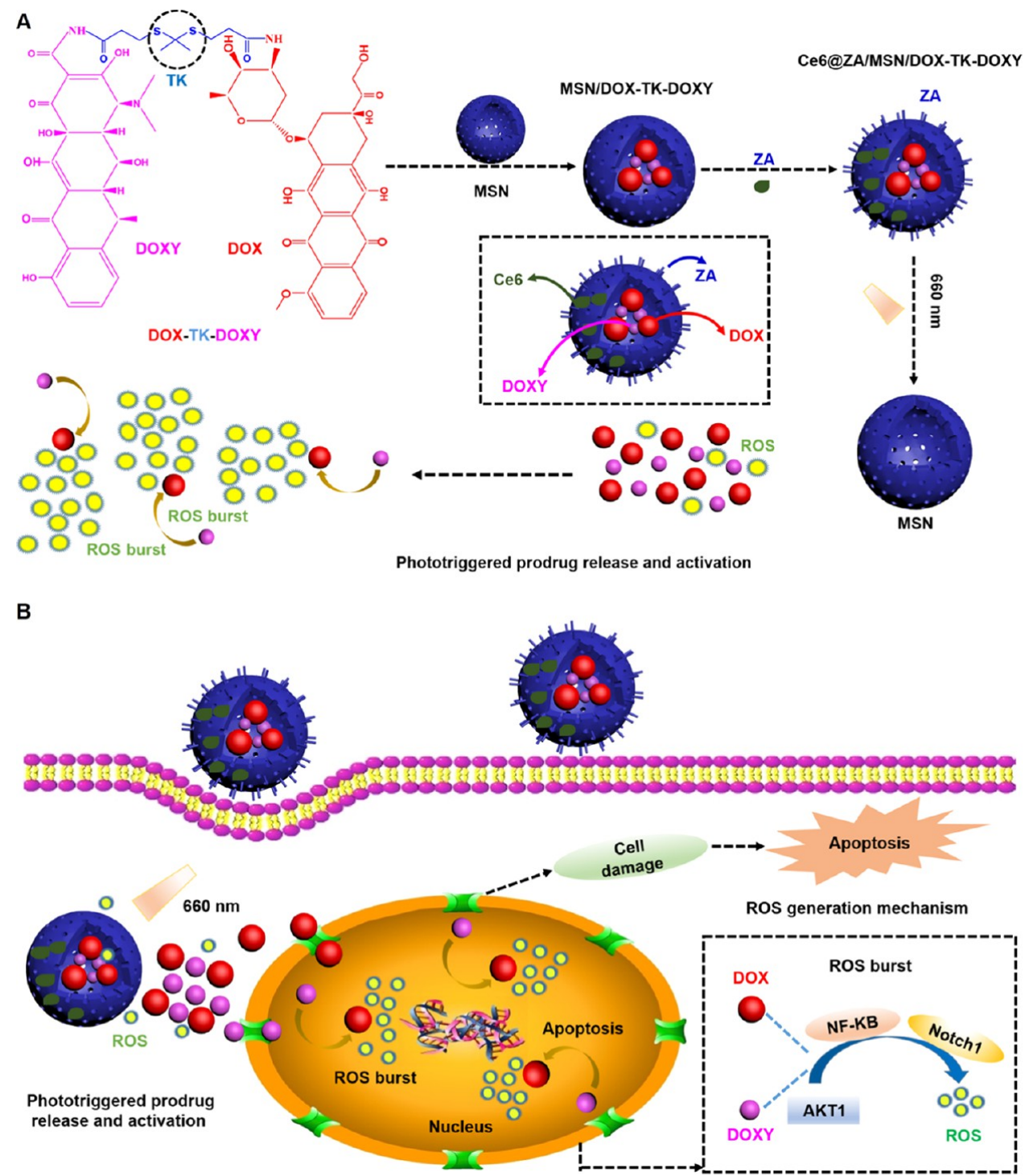

${ }^{a}$ Upon laser irradiation, the loaded Ce6 produces in situ ROS, which results in fast disruption of the TK linkage. The released drugs amplify ROS generation for enhanced chemodynamic therapy of osteosarcoma

as the first-line therapy for osteosarcoma, whereas doxycycline (DOXY) has efficient cytotoxic and anti-proliferative effects on various cancer cells and improves the chemotherapy of DOX. $^{26-29}$ Therefore, the combination of these two drugs should have a synergistic effect on the inhibition of tumor cell proliferation and apoptosis. As shown in Scheme 1, DOX and DOXY with a thioketal (TK) linkage (DOX-TK-DOXY) was synthesized as a prodrug and was further loaded into the mesoporous silica nanoparticles (MSNs), followed by surface modification of bone-targeting zoledronic acid (ZA) and adsorption of the photosensitizer chlorin e6 (Ce6). The loaded Ce6 would produce intracellular ROS upon laser irradiation after our nanoreactor was uptaken by tumor cells, which would disrupt the TK linkage of the prodrug in the meantime, leading to synchronous release of both DOX and DOXY. The released DOXY was supposed to promote the production of ROS and therefore result in subsequent amplification of DOX and DOXY release and a final ROS burst. With bone-targeting capability and ROS burst, we assumed that our nanoreactors should have excellent tumor inhibition toward osteosarcoma.

\section{RESULTS AND DISCUSSION}

The prodrug DOX-TK-DOXY was first synthesized via the formation of amide bonds between carboxyl from ketothiols and amido from drugs, and the obtained product was confirmed by proton nuclear magnetic resonance $\left({ }^{1} \mathrm{H}\right.$ NMR) spectroscopy (Figure S1, Supporting Information). Then, the prodrug DOX-TK-DOXY was incubated with MSNs (MSNs were prepared according to the previous literature $)^{30}$ for $54 \mathrm{~h}$ to achieve successful drug-loading process. The loading efficiencies of DOX and DOXY were $\sim 12.3$ and $\sim 5.1 \%$, respectively, due to the different ratio between the added DOX and DOXY during the synthesis of 

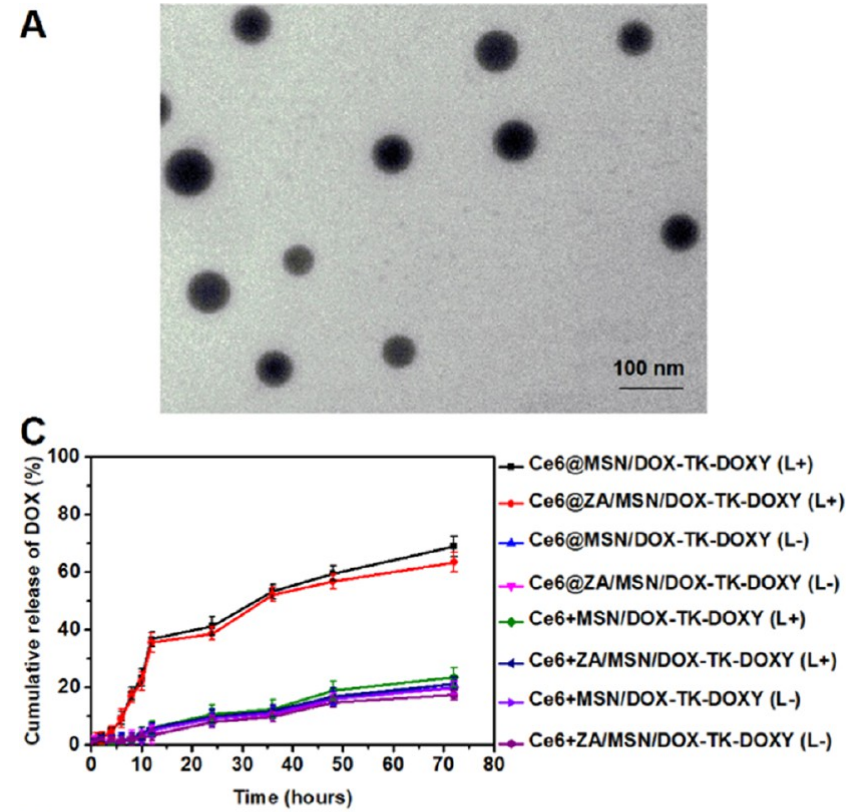

$\mathbf{E}$

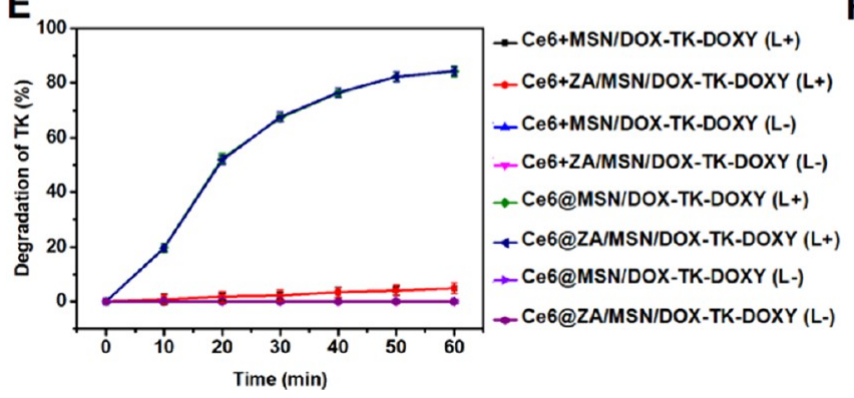

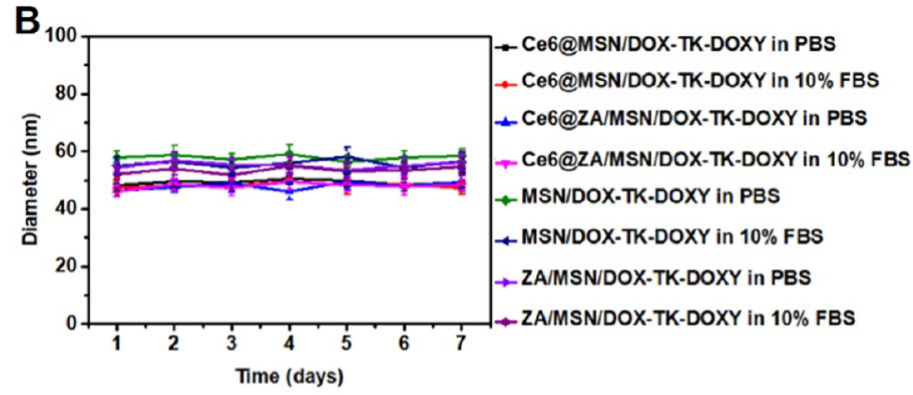

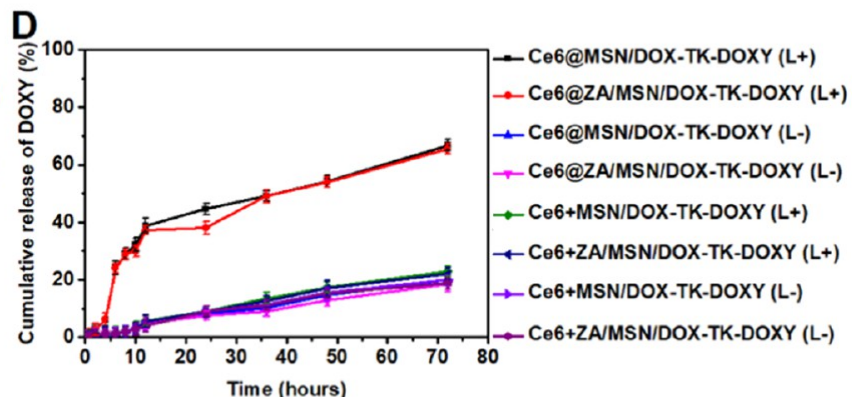

$\mathbf{F}$
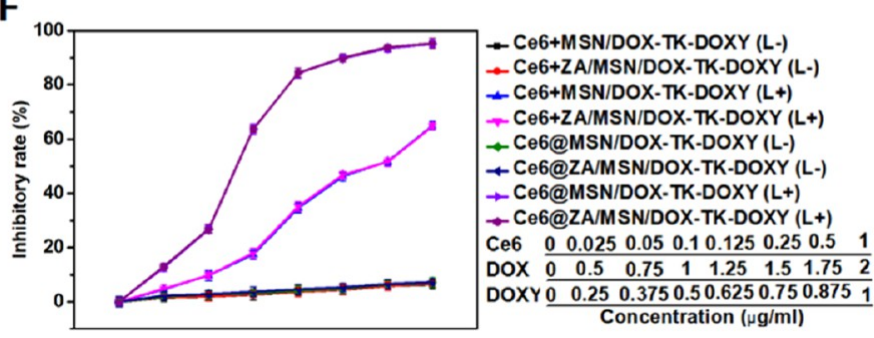

Figure 1. Characterization of Ce6@ZA/MSN/DOX-TK-DOXY. (A) TEM image of Ce6@ZA/MSN/DOX-TK-DOXY. (B) Stability of Ce6@ ZA/MSN/DOX-TK-DOXY in different medium (PBS and FBS). (C,D) DOX and DOXY release profiles of Ce6@ZA/MSN/DOX-TK-DOXY in PBS. (E) Degradation of TK linkage of Ce6@ZA/MSN/DOX-TK-DOXY in PBS. The loaded Ce6 was a prerequisite for the degradation of the TK bond and subsequent phototriggered DOX and DOXY releases. (F) Cell growth inhibition after incubation with different samples. Data were represented as mean $\pm S D(n=3)$. Data are shown with or without $660 \mathrm{~nm}$ laser irradiation at $0.1 \mathrm{~W} \mathrm{~cm}^{-2}$ for $20 \mathrm{~min}$.

the prodrug. Four different biphosphate (BP) compounds namely etidronate disodium (ET), pamidronate disodium (PA), alendronate disodium (AId), or zoledronic acid (ZA) were then covalently attached onto the surface of MSNs separately and the bone-targeting efficiencies of the formed nanostructures were further evaluated. According to inverted fluorescence, flow cytometry, and the TUNEL results (Figures S2 and S3, Supporting Information), ZA was found as the strongest bone-targeting moiety among the four BP compounds. Therefore, ZA was selected for the following experiments with the grafting percentage of $27.6 \%$. The photosensitizer Ce6 was adsorbed subsequently onto the surface of the formed structure as a trigger for controlled drug release and ROS burst, which is hereafter referred to as Ce6@ ZA/MSN/DOX-TK-DOXY. The loading content of Ce6 was $2.22 \pm 0.08 \%$ (weight ratio) when a feed ratio of $5: 10(\mathrm{w} / \mathrm{w}$, Ce6/ZA/MSN/DOX-TK-DOXY) was applied (Figure S4, Supporting Information). After prodrug/Ce6 loading and ZA attachment, the samples were characterized by dynamic light scattering (DLS) and transmission electron microscopy (TEM), respectively (Figure S5, Supporting Information and Figure 1A). The hydrodynamic size of the formed Ce6@ZA/ MSN/DOX-TK-DOXY was around $\sim 40 \mathrm{~nm}$ according to DLS measurement (Figure S5, Supporting Information). The size was quite stable for $7 \mathrm{~d}$ (Figure 1B) in both phosphate- buffered saline (PBS) and 10\% fetal bovine serum (FBS) solution. The UV-vis spectra of Ce6@MSN/DOX-TKDOXY (Figure S6A, Supporting Information) displayed the same absorption peak with the free DOX, DOXY, and Ce6, suggesting the successful encapsulation of prodrug DOX-TKDOXY and Ce6.

After confirming the desired structure, a red light with a wavelength of $660 \mathrm{~nm}$ was used for ROS production based on the loaded Ce6. The TK linkage of the prodrug is sensitive to ROS; therefore, the loaded Ce6 functioned as a trigger for the controlled drug release from the encapsulated prodrug. All samples were treated with or without laser irradiation at $0.1 \mathrm{~W}$ $\mathrm{cm}^{-2}$ for $20 \mathrm{~min}$ before sampling. As shown in Figure $1 \mathrm{C}, \mathrm{D}$, $\sim 16.79 \%$ of DOX $(8 \mathrm{~h})$ and $\sim 23.99 \%$ of DOXY (6 h) were rapidly released from Ce6@ZA/MSN/DOX-TK-DOXY during laser irradiation, whereas almost no release was observed for the group without laser treatment. Moreover, the releasing amount of DOX and DOXY reached $\sim 63.46$ and $\sim 65.49 \%$, respectively, by $72 \mathrm{~h}$. After $144 \mathrm{~h}, 76.89 \%$ of DOX and $78.34 \%$ of DOXY were released (Figure S6B,C, Supporting Information), indicating the long-term drug release of the formed nanostructure. Whereas for the physical mixing group $(\mathrm{Ce} 6+\mathrm{ZA} / \mathrm{MSN} / \mathrm{DOX}-\mathrm{TK}-\mathrm{DOXY})$ after laser irradiation, no obvious drug release was observed, although a large amount of ROS was produced (Figure S6D, Supporting Information), 

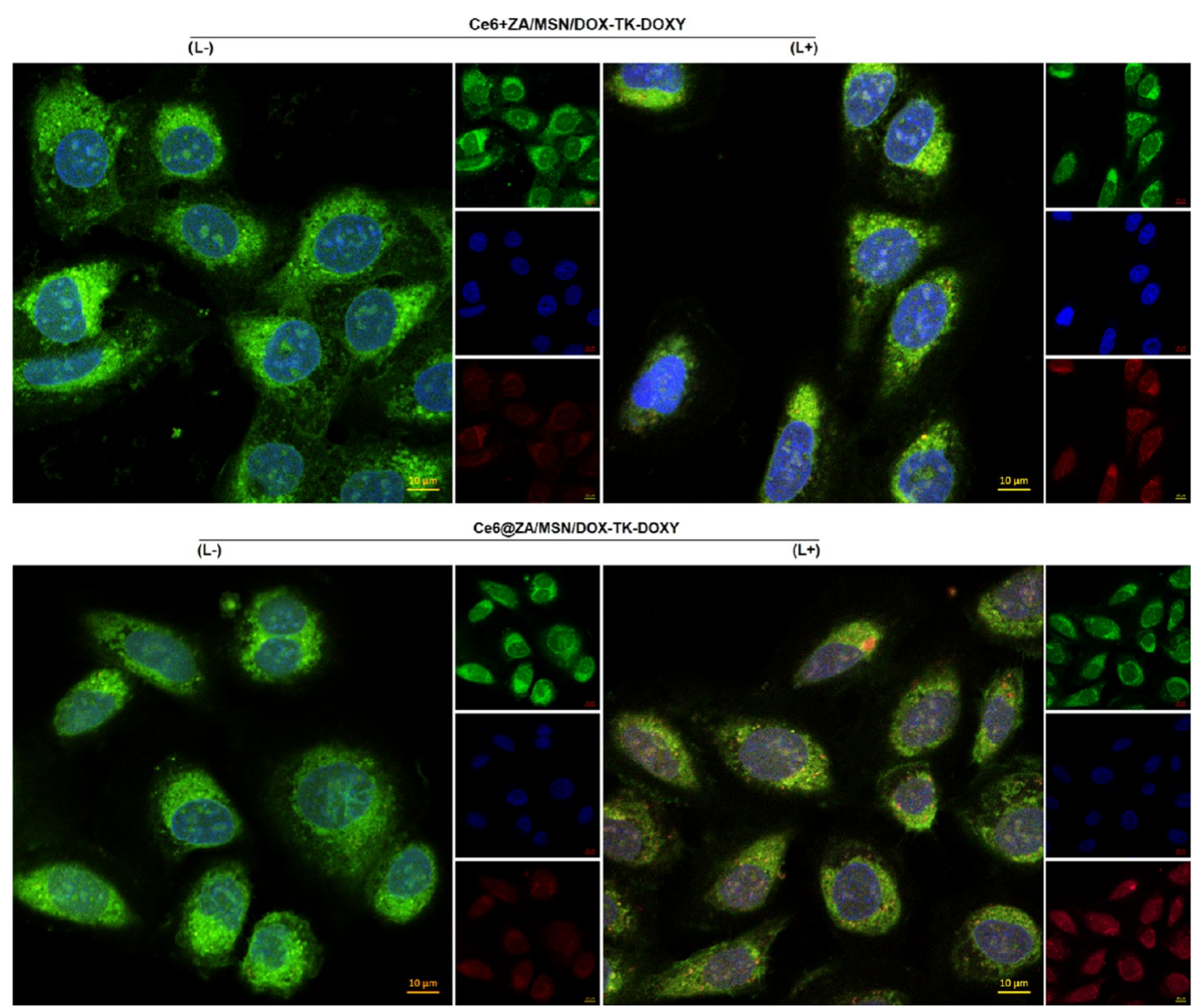

Ce6@ZA/MSN/DOX-TK-DOXY $(\mathrm{L}+)$

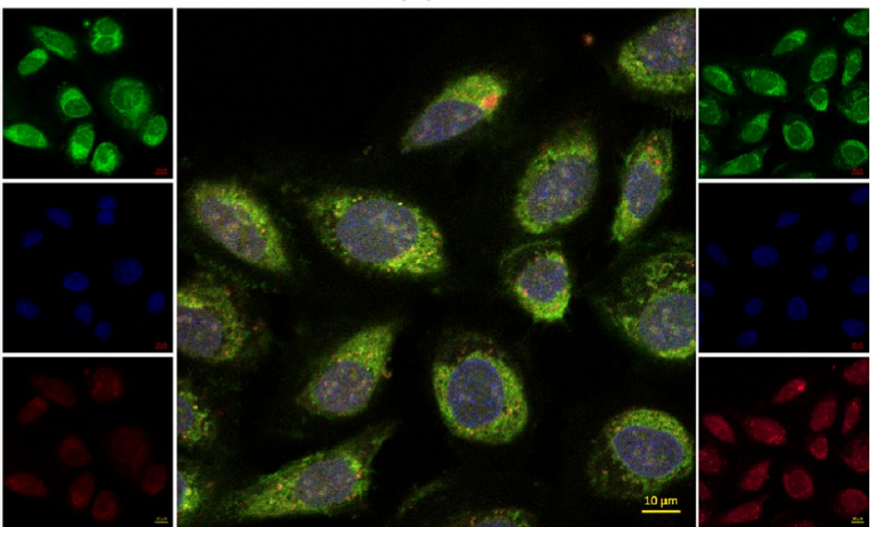

Figure 2. Phototriggered intracellular DOX and DOXY release. Confocal microscopy images of OS-732 cells after incubating with Ce6@ZA/ MSN/DOX-TK-DOXY for $4 \mathrm{~h}$, followed by laser irradiation and further incubation for $6 \mathrm{~h}$. [red = DOX; green = cytomembrane, Alexa Fluor 488; blue = nucleus, 4',6-diamidino-2-phenylindole (DAPI) $]$. The cells were treated with or without laser irradiation at $0.1 \mathrm{~W} \mathrm{~cm}^{-2}$ for $20 \mathrm{~min}$.

probably because in situ ROS production was important for the rapid disruption of the $T K$ linkage.

Thereafter, the disruption of the TK linkage of the prodrug under laser irradiation was also evaluated. According to the previous reports, the $T K$ linkage could be transformed into two thiol terminal groups by ROS, ${ }^{31,32}$ therefore the degradation rate could be measured by detecting the amount of produced thiol groups using Ellman's test. ${ }^{33,34}$ As shown in Figure 1E, no degradation occurred before laser treatment. Whereas after irradiation, the disruption of the $T K$ linkage was augmented remarkably with the prolongation of the irradiation time. It was clearly demonstrated that approximately 51.9 and $76.5 \%$ of the $T K$ linkage was cleaved after laser irradiation for 20 and $40 \mathrm{~min}$, respectively. However, less than $\sim 10 \%$ was degraded even after irradiating for $60 \mathrm{~min}$ when Ce6 was mixed with ZA/MSN/DOX-TK-DOXY physically. It can be attributed to the in situ ROS production by the loaded Ce6 under laser irradiation, which was also a precondition for the fast degradation of the $T K$ linkage and subsequently phototriggered DOX and DOXY release. ${ }^{35}$ Osteosarcoma cell lines (OS-732 cells) were used as model osteosarcoma cells for following in vitro experiments. Compared to the samples without irradiation, significant cell growth inhibition was observed for both Ce6@MSN/DOXTK-DOXY and Ce6@ZA/MSN/DOX-TK-DOXY after laser treatment (Figures $1 \mathrm{~F}$ and S6E, Supporting Information).

To evaluate the drug release from the nanostructure after cellular uptake, OS-732 cells were treated with different formations for $6 \mathrm{~h}$. The resulting OS-732 cells were then washed and subjected to laser irradiation at $0.1 \mathrm{~W} \mathrm{~cm}^{-2}$ for 20 min, followed by further culturing for $6 \mathrm{~h}$. Normally free DOX is translocated fleetly into the nuclei, and it remains in the nuclei rather than in the cytoplasm. Before illumination, the red fluorescence from DOX around the nuclei was observed (Figures 2 and S7, Supporting Information), which indicated that Ce6@ZA/MSN/DOX-TK-DOXY was uptaken and the loaded prodrug remained stable. Upon light irradiation, obvious red fluorescence was found within the nuclei, demonstrating that the released DOX from the prodrug triggered by laser could enter into the nuclei. Thereafter, fluorescence intensity of DOX and intracellular concentrations of DOX and DOXY were measured and are shown in Figure S8A-C, Supporting Information. There was negligible difference in intracellular DOX and DOXY concentrations whether the laser was applied or not. However, the fluorescence intensity did have significant difference probably because the loaded Ce6 produced in situ ROS, resulting in triggered release of DOX and DOXY efficiently. Because of the $\pi-\pi$ stacking of loaded DOX (decreased fluorescence intensity), the fluorescence of DOX rose after releasing. ${ }^{11}$

In order to confirm the ROS burst of our design, ROS probe $2^{\prime}-7^{\prime}$-dichlorofluorescin diacetate (DCFH-DA) was used to detect the intracellular ROS production. It should be noted that DCFH-DA can permeate into cells and then be degraded by intracellular lipase and converted into DCFH. While the formed DCFH can be further oxidized into 


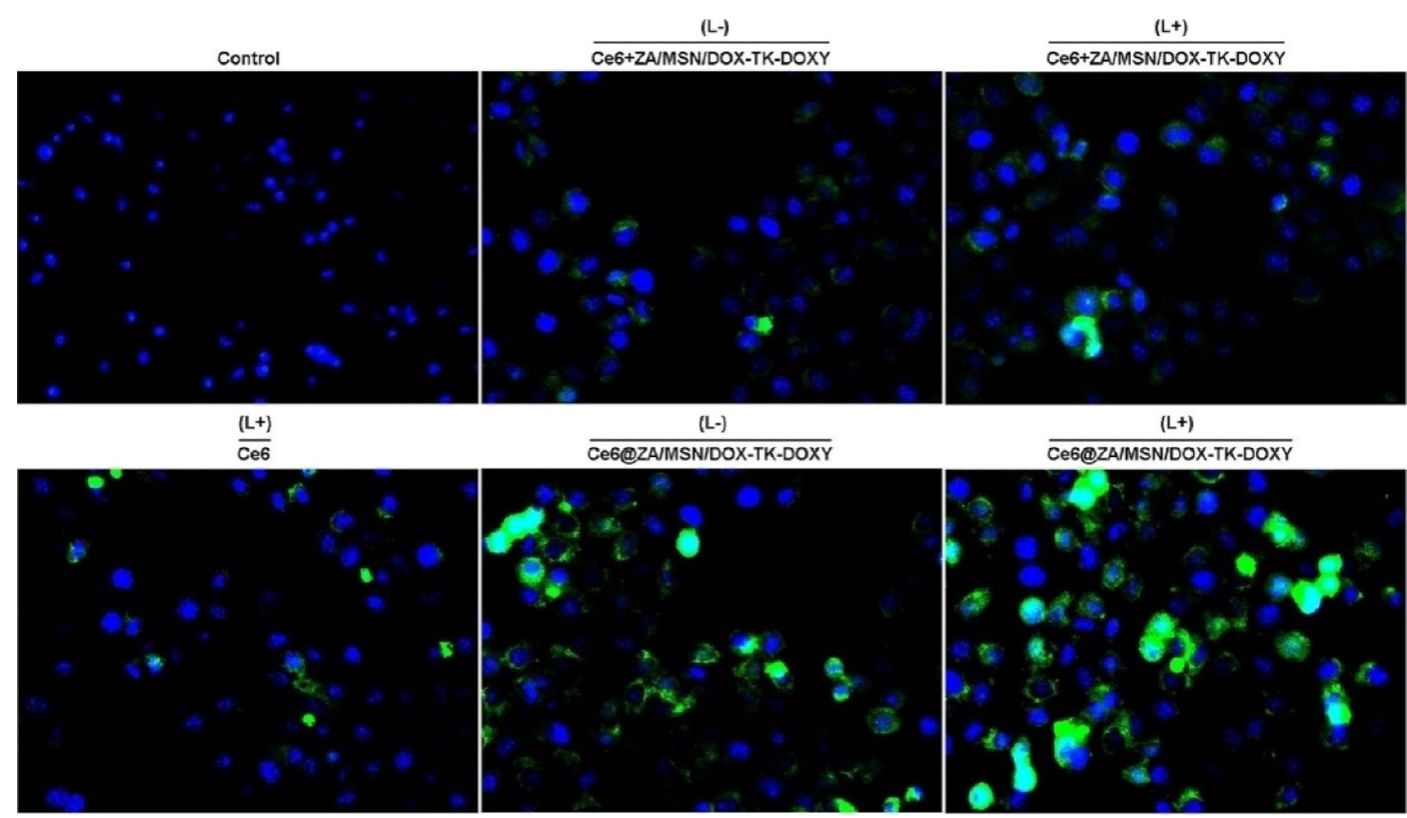

Figure 3. Intracellular ROS production using DCFH-DA as an indicator. The concentrations of Ce6, DOX, and DOXY were 0.125, 1.25 , and $0.625 \mu \mathrm{g} \mathrm{mL}^{-1}$, respectively (with or without $660 \mathrm{~nm}$ laser irradiation at $0.1 \mathrm{~W} \mathrm{~cm}^{-2}$ for $20 \mathrm{~min}$ ).

fluorescent DCF, which has a positive correlation with intracellular ROS level. As shown in Figure 3, fluorescence intensity of intracellular DCF increased about six times for Ce6@ZA/MSN/DOX-TK-DOXY after laser treatment, indicating the occurance of ROS burst upon irradiation. Although no significant increase was observed for the physically mixed group. The loaded $\mathrm{Ce} 6$ could produce in situ ROS under laser, which triggered the release of the prodrug. The released DOXY resulted in further ROS production, leading to subsequent DOX/DOXY release and ROS burst. In addition, flow cytometry was further used to compare quantitatively the intracellular ROS contents after different treatments (Figure S9A,B, Supporting Information). The quantitative results uncovered that the ROS levels after treatment significantly increased when compared with the control groups, implying that Ce6@ZA/MSN/DOX-TKDOXY could remarkably induce ROS burst.

Live (green)/dead (red) staining (Figure 4A) was further used to evaluate in vitro toxicity, which was consistent with the MTT results. Upon laser irradiation, almost all cells treated with Ce6@ZA/MSN/DOX-TK-DOXY were dead and displayed the most intensive red fluorescence. Moreover, cell apoptosis, cell cycle, and mitochondrial transmembrane potential (MTP) were also carried out to estimate cell damage. $^{11,36-39}$ As shown in Figure $4 \mathrm{~B}$, the proportion of apoptotic OS-732 cells was remarkably increased to $84.8 \pm$ $3.84 \%$ after treating with Ce6@ZA/MSN/DOX-TK-DOXY $(\mathrm{L}+)$, representing the highest apoptosis rates among all groups (Figure 4B), which was further confirmed by the TUNEL results (Figure S10, Supporting Information). The $\mathrm{G} 2 / \mathrm{M}$ phase $(26.9 \pm 1.82 \%)$ of the OS-732 cells was also measured, demonstrating highest cell cycle rates of Ce6@ZA/ MSN/DOX-TK-DOXY (L+) (Figure 4C). Furthermore, the MTP results (Figure S11, Supporting Information) revealed that the fluorescence intensity after treatment was significantly reduced to $132.4 \pm 8.2$ when compared with the control groups $(212.4 \pm 11.3)$, indicating that Ce6@ZA/MSN/DOXTK-DOXY could reduce MTP significantly to induce apoptosis. Enhanced intracellular metabolism and ameliorated tumor metabolic disorders were also observed according to ${ }^{1} \mathrm{H}$ NMR measurement (Figure S12, Supporting Information). Therefore, our design had the highest efficacy in terms of the inhibition of tumor cell growth.

The tumor targeting ability and biodistribution of Ce6@ ZA/MSN/DOX-TK-DOXY was further assessed by magnetic resonance (MR) and in vivo fluorescence imaging. According to the literature, ${ }^{40}$ the adsorbed photosensitizer Ce6 can be used as a chelating agent to capture gadolinium-III, thereby enabling $T_{1}$ contrast in $\mathrm{MR}$ imaging. Therefore, crosssectional $T_{1}$ and $T_{2}$ MR imaging was performed in OS-732 tumor-bearing mice after intravenous injection of Ce6-Gd@ ZA/MSN/DOX-TK-DOXY. As shown in Figure 5A, $T_{1}$ MR intensity in the tumor region gradually increased with the strongest signal observed in $6 \mathrm{~h}$ post-injection, indicating the efficient tumor targeting of our Ce6-Gd@ZA/MSN/DOXTK-DOXY. As for $T_{2} \mathrm{MR}$ imaging (Figure 5B), the bone structure changed with time after treatment.

In addition, Ce6, as a fluorescent dye, can also be exploited for in vivo fluorescence imaging of tumors. ${ }^{41}$ The maximum fluorescence excitation wavelength of Ce6 is $403 \mathrm{~nm}$, and the maximum fluorescence emission wavelength is $669 \mathrm{~nm}$. The relative fluorescence intensity of Ce6@ZA/MSN/DOX-TKDOXY in the tumor region was three-fold higher than that of free Ce6 at $6 \mathrm{~h}$, showing excellent tumor-targeting ability of our nanoparticles (Figure 5C). After $24 \mathrm{~h}$ of injection, the mice were sacrificed and the main organs including tumors were collected to analyze their detailed biodistribution profiles. As shown in Figure 5D, the tumors exhibited the highest fluorescence signal when Ce6@ZA/MSN/DOX-TKDOXY was administrated.

Encouraged by the efficient accumulation of Ce6@ZA/ MSN/DOX-TK-DOXY in the tumor site, we then assessed the in vivo antitumor efficacy with mice bearing a OS-732 tumor. Because of the fast growth of osteosarcoma, distal and osteolytic destruction occurred in the distal femur, and soft tissue masses were formed outside the bone marrow cavity. 
A
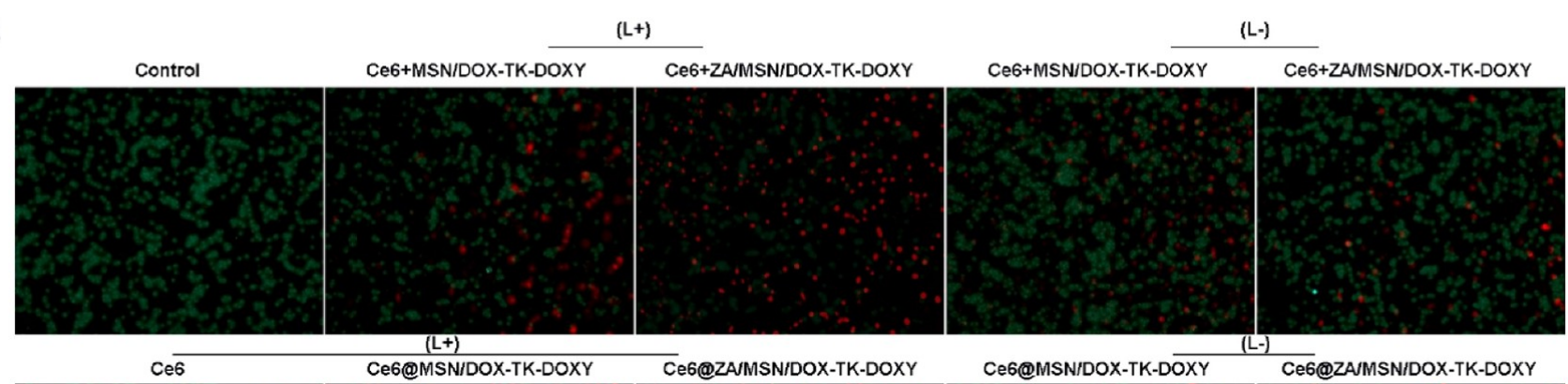

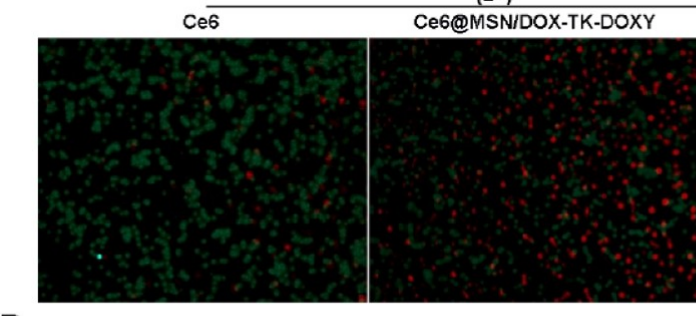

B

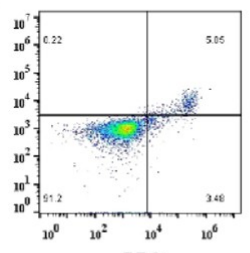

PBS

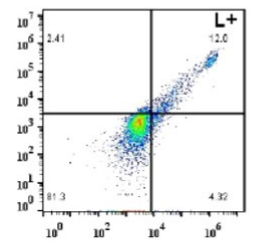

Ce6+MSN/DOX-TK-DOXY Ce6+ZA/MSN/DOX-TK-DOXY

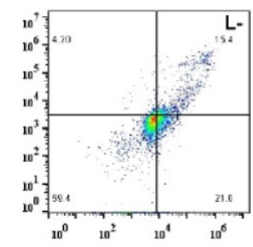

Ce6@ZAIMSNIDOX-TK-DOXY

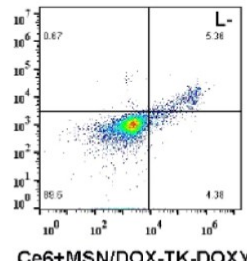

Ce6+MSN/DOX-TK-DOX
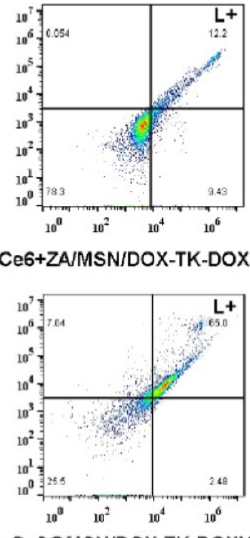

Ce6@MSNIDOX-TK-DOXY
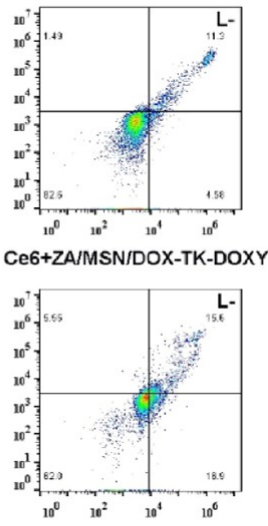

Ce6@MSN/DOX-TK-DOXY

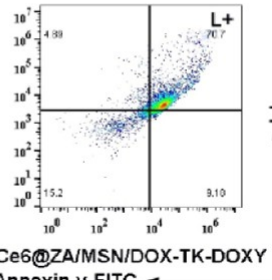

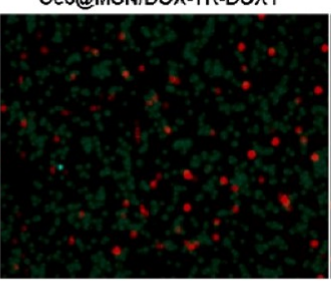

C
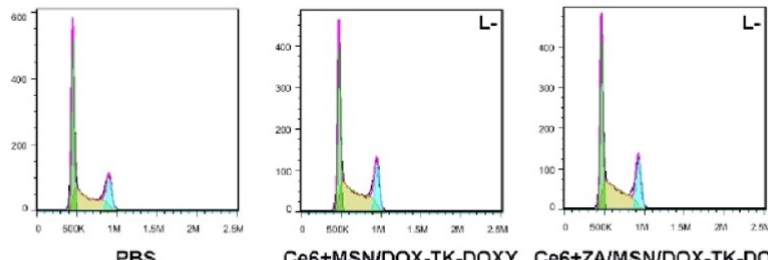

Ce6+MSN/DOX-TK-DOXY Ce6+ZA/MSN/DOX-TK-DOXY
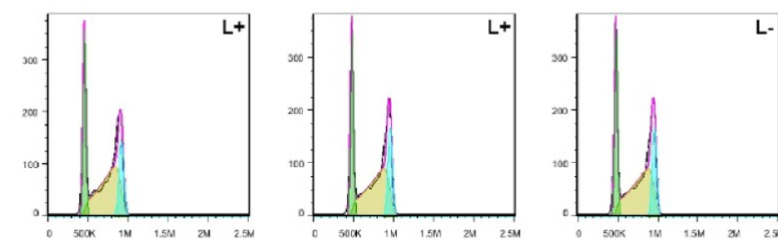

Ce6+MSN/DOX-TK-DOXY Ce6+ZA/MSN/DOX-TK-DOXY Ce6@/MSN/DOX-TK-DOXY
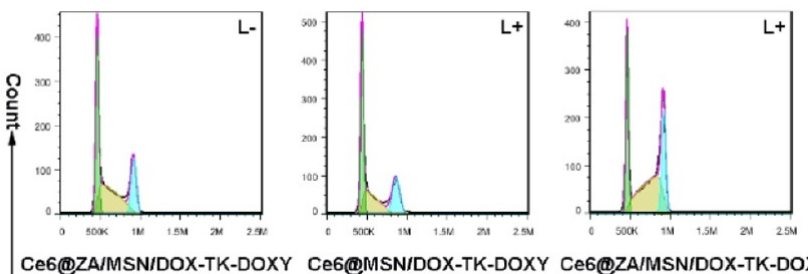

Ce6@ZA/MSN/DOX-TK-DOXY Ce6@MSNIDOX-TK-DOXY Ce6@ZAIMSNIDOX-TK-DOXY

Figure 4. In vitro synergistic role of Ce6@ZA/MSN/DOX-TK-DOXY after laser irradiation. (A) Living and dead staining of OS-732 cells with different treatments. The concentration of Ce6, DOX, and DOXY was $0.125,1.25$, and $0.625 \mu \mathrm{g} \mathrm{mL}^{-1}$, respectively. (B) Apoptosis and (C) cell cycle analysis of OS-732 cells after different treatments (with or without $660 \mathrm{~nm}$ laser irradiation at $0.1 \mathrm{~W} \mathrm{~cm}^{-2}$ for $20 \mathrm{~min}$ ).

Moreover, bone defects were further enlarged in the medullary cavity, along with cortical thinning and osteoporosis. Therefore, the used red light with $600 \mathrm{~nm}$ is able to penetrate into the bone due to bone defect induced by the osteosarcoma. Mice were injected intravenously and the concentrations of DOX and DOXY over time were measured by highperformance liquid chromatography (HPLC). As shown in Figure $6 \mathrm{~A}, \mathrm{~B}$, our design clearly prolonged the circulation of DOX or DOXY in the blood compared with free drugs. The tumor sizes were recorded for 16 days, after which the tumors were collected and weighted (Figure 6C,D). The tumor relative growth was also calculated accordingly (Figure 6E). The body weights of the mice during the treatment were quite stable, suggesting no acute toxicity of our Ce6@ZA/MSN/ DOX-TK-DOXY (Figure S13, Supporting Information). As expected, the tumor sizes did not exhibit significant decrease for Ce6@ZA/MSN/DOX-TK-DOXY. Only after the laser irradiation, the mice gained best tumor inhibition effect and the tumor volume was suppressed by $66.7 \%$ compared with that in the PBS group. In our design, in situ ROS produced by Ce6 upon irradiation led to controlled release of DOX and DOXY. The released DOXY further induced the ROS production, resulting in fast release of antitumor drugs and subsequent ROS burst. Therefore, efficient antitumor efficacy of Ce6@ZA/MSN/DOX-TK-DOXY after laser treatment was observed. In the meanwhile, qualitative and quantitative intratumoral ROS were further analyzed to confirm the in situ ROS burst. Upon laser irradiation, significant in situ ROS was generated for Ce6@ZA/MSN/DOX-TK-DOXY when compared with control groups (Figure S14A,B). In addition, the degree of tumor circulation and the vascular density area of neovascularization were also detected (Figures S15-S17, Supporting Information). Reduced tumor circulation and a smaller vascular density area of neovascularization were observed after treatment, demonstrating that Ce6@ZA/ MSN/DOX-TK-DOXY could inhibit the process of neo- 

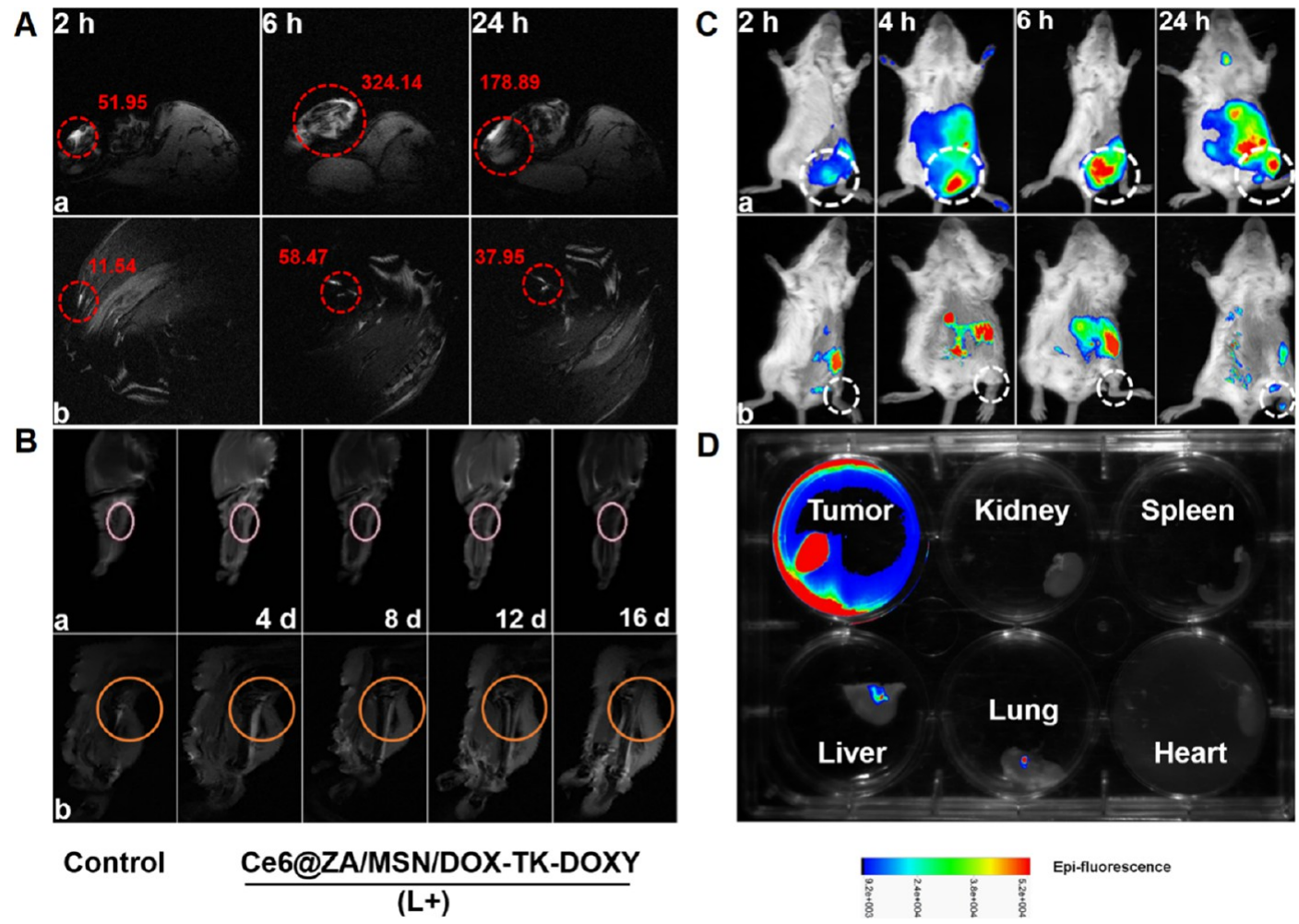

Figure 5. In vivo distribution of Ce6@ZA/MSN/DOX-TK-DOXY. (A) $T_{1}$ MR images of tumor-bearing mice after vein injection of Ce6-Gd@ ZA/MSN/DOX-TK-DOXY [(a) Ce6-Gd@ZA/MSN/DOX-TK-DOXY; (b) DTPA-Gd] with OD values. (B) $T_{2}$ MR images of tumor-bearing mice after vein injection of Ce6@ZA/MSN/DOX-TK-DOXY [(a) Ce6@ZA/MSN/DOX-TK-DOXY; (b) Ce6 + ZA/MSN/DOX-TK-DOXY]. (C) In vivo fluorescence distribution of Ce6@ZA/MSN/DOX-TK-DOXY (a) and Ce6 + ZA/MSN/DOX-TK-DOXY (b) in tumor-bearing mice at different time points. (D) Ex vivo tissue distribution of sacrificed mice at $24 \mathrm{~h}$ after the injection $(n=5)$.

vascularization to reduce local blood supply in tumor tissue, thus inhibiting the proliferation of the tumor. Furthermore, serum alkaline phosphatase level, as an important indicator for osteosarcoma, was also decreased obviously, indicating the efficiency of our design (Figure 6F).

Pathological sections and protein expression of the main organs were further analyzed by hematoxylin-eosin (HE) staining, immunochemistry, and RT-PCR (Figures S18 and S19, Supporting Information; Figures 6G and 7). According to the results, our nanodrugs displayed negligible toxicity toward main organs, which could be attributed to efficient bone targeting and in situ ROS-induced drug release. Next, the biodistribution of DOX and DOXY was also quantitatively detected. Tumor-bearing mice were intravenously injected with Ce6@ZA/MSN/DOX-TK-DOXY with equivalent DOX and DOXY dosages of 5.0 and $2.5 \mathrm{mg} \mathrm{kg}^{-1}$. The mice were subsequently sacrificed, and their organs including tumors were collected for HPLC analysis. As shown in Figure S20, Supporting Information, the concentrations of DOX and DOXY in tumor tissues from Ce6@ZA/MSN/DOX-TKDOXY were obviously higher than those with free drugs, further confirming the efficient bone-targeting capability.

\section{CONCLUSIONS}

In summary, we have successfully demonstrated the fabrication of a bone-targeting prodrug nanoreactor (Ce6@ ZA/MSN/DOX-TK-DOXY) with ROS burst for enhanced chemotherapy toward osteosarcoma. As a prodrug, DOX and DOXY with TK linkage was loaded into MSNs, followed by attachment of a bone-targeting moiety and subsequent absorption of photosensitizer Ce6. Upon laser irradiation, the absorbed Ce6 produced ROS, resulting in the triggered release of DOX and DOXY. The released DOXY induced ROS production, which led to subsequent DOX/DOXY release and ROS burst, improving the efficacy of chemotherapy for osteosarcoma. Our work thus presents a smart strategy to combine ROS-triggered prodrug release and released drug-induced ROS burst to achieve a chemodynamic therapy. We expect that such a strategy may also apply to development of novel multifunctional nanoplatforms for personalized tumor therapy. However, because of the limited penetrating depth of the laser we used in the present report, the laser with the wavelength in the NIR region should be considered. In addition, future studies are still needed in order to prevent phagocytosis with longer circulation times of our nanoreactors by introducing stealth strategy.

\section{EXPERIMENTAL SECTION}

Materials. DOX hydrochloride $(\mathrm{DOX} \cdot \mathrm{HCl})$ was bought from Beijing Blue Wood Technology Co. Ltd. (China). DOXY was purchased from Saen Chemical Technology (Shanghai) Co. Ltd. (China). Chlorin e6 (Ce6) was obtained from Guangzhou Xiangbo Biotechnology Co. Ltd. (China). Alkaline phosphatase kit was obtained from Inner Mongolia Hongji Biotechnology Co. Ltd. (China). Osteopontin/secretory phosphoprotein-1 antibody was bought from Shenzhen Xinhailing Biotechnology Co. Ltd. (China). NF-kB p65 and AKT1 antibodies and ROS detection kit were obtained from Guangzhou Persie Biotechnology Co. Ltd. (China). Notch1 antibody was bought from Guangzhou Jiwei Biotechnology Co. Ltd. (China). 9,10-Anthracenediyl-bis (methylene) dimalonic acid was purchased from Beijing Qiansanlian Biotechnology Co. Ltd. (China). 5,5'-Dithiobis (2-nitrobenzoic acid) was obtained from 

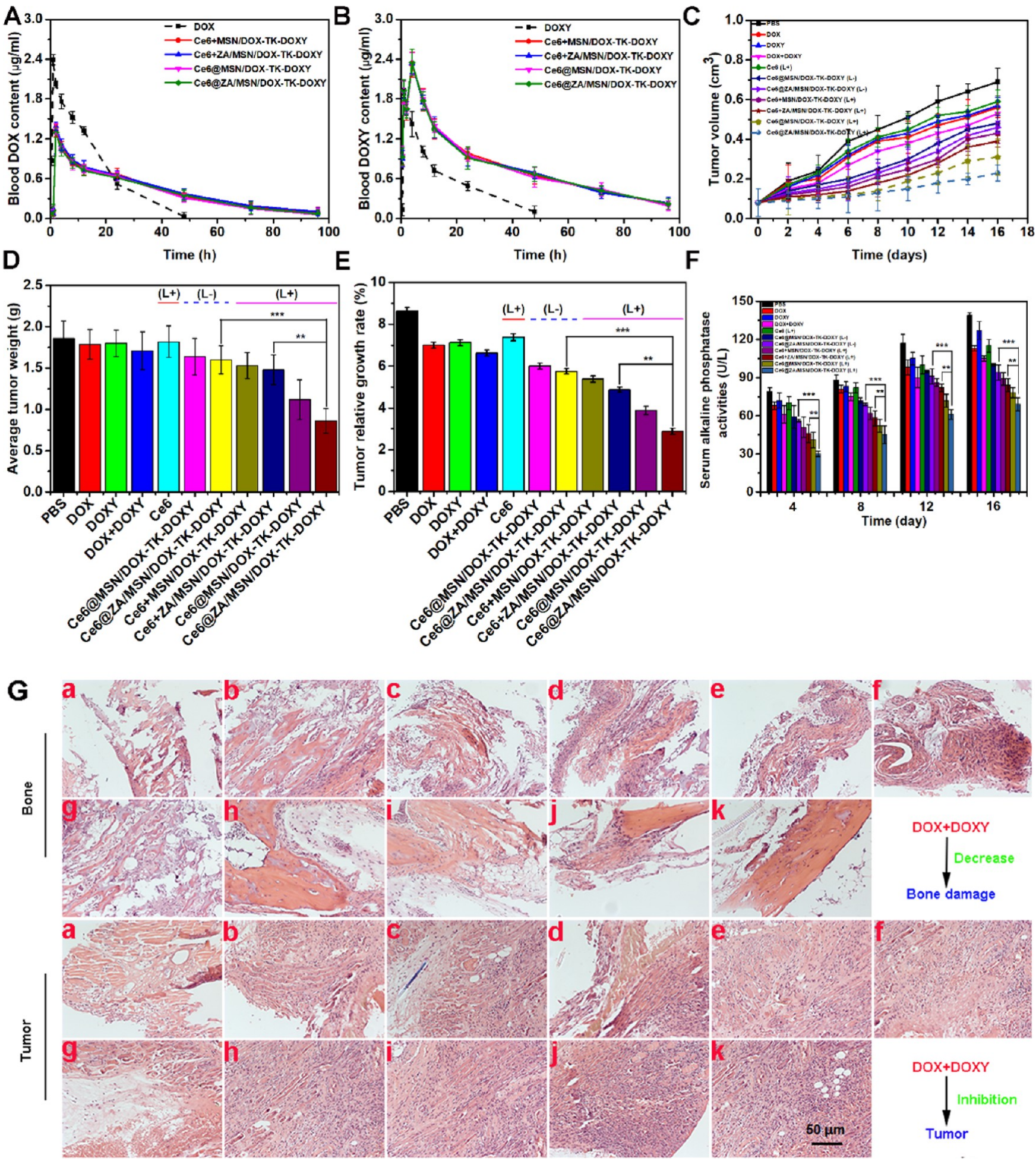

Figure 6. In vivo pharmacological effects of Ce6@ZA/MSN/DOX-TK-DOXY. (A) Plasma DOX concentration over time after intravenous injection of Ce6@ZA/MSN/DOX-TK-DOXY. (B) Plasma DOXY concentration over time after intravenous injection of Ce6@ZA/MSN/DOXTK-DOXY. (C) Tumor volume, (D) mean tumor weight, (E) tumor relative growth, (F) serum alkaline phosphatase, and $(\mathrm{G}) \mathrm{HE}$ [a = control; $\mathrm{b}$ = DOX; c = DOXY; d = DOX + DOXY; e = Ce6@MSN/DOX-TK-DOXY (L-); f = Ce6@ZA/MSN/DOX-TK-DOXY (L-); g = Ce6 (L+); h = Ce6 + MSN/DOX-TK-DOXY (L+); i = Ce6 + ZA/MSN/DOX-TK-DOXY (L+); j = Ce6@MSN/DOX-TK-DOXY (L+); and k = Ce6@ZA/ MSN/DOX-TK-DOXY $(\mathrm{L}+)]$ of tumor-bearing mice after different treatments. Statistical analysis was accomplished by ANOVA and post hoc analysis $(* * P<0.05, * * * P<0.01)$. Data are presented as means $\pm S D(n=5) .660 \mathrm{~nm}$ laser was irradiated with $0.1 \mathrm{~W} \mathrm{~cm}^{-2}$ for $30 \mathrm{~min}$ at $6 \mathrm{~h}$ post-injection.

Beijing Green Baicao Technology Development Co. Ltd. (China). ZA was procured from Shanghai McLean Biochemical Technology Co. Ltd. (China). The total sulfhydryl test kit was bought from
Wuhan Anges Biotechnology Co. Ltd. (China). Regenerated cellulose dialysis membrane (MWCO: $1000 \mathrm{Da}$ ) from Shanghai Jizhi Biochemical Technology Co. Ltd. (China) was used for dialysis. 


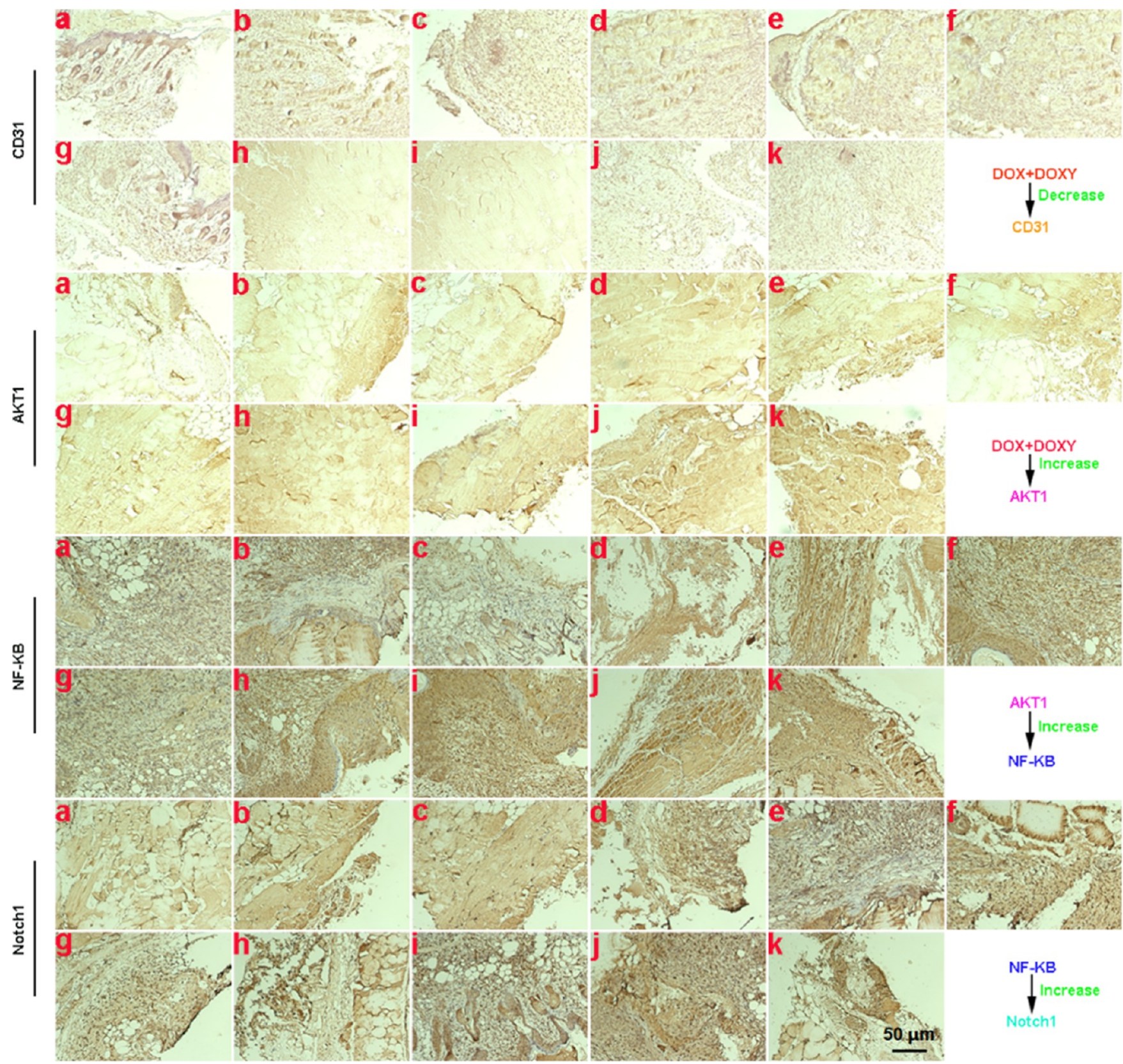

Figure 7. Superior anticancer efficacy of Ce6@ZA/MSN/DOX-TK-DOXY [a = control; b = DOX; c = DOXY; d = DOX + DOXY; e = Ce6@ MSN/DOX-TK-DOXY (L-); f = Ce6@ZA/MSN/DOX-TK-DOXY (L-); g = Ce6 (L+); h = Ce6 + MSN/DOX-TK-DOXY (L+); i = Ce6 + ZA/MSN/DOX-TK-DOXY (L+); j = Ce6@MSN/DOX-TK-DOXY (L+); k = Ce6@ZA/MSN/DOX-TK-DOXY (L+)]. Immunochemistry was used for the observation of the changes after intravenous administration $(n=5) .660 \mathrm{~nm}$ laser was applied with $0.1 \mathrm{~W} \mathrm{~cm}{ }^{-2}$ for $30 \mathrm{~min}$ at $6 \mathrm{~h}$ post-injection.

Synthesis of DOX-TK-DOXY. ROS-responsive TK $(0.2 \mathrm{mmol})$ was dissolved in anhydrous dimethylformamide (DMF), followed by the addition of N-Hydroxysuccinimide (NHS, $0.6 \mathrm{mmol})$ and 1-(3Dimethylaminopropyl)-3-ethylcarbodiimide (EDC, $0.6 \mathrm{mmol})$ under $\mathrm{N}_{2}$. After stirring for $2 \mathrm{~h}$, DOX (108 mg) in anhydrous DMF was added dropwise to acquire DOX-TK. After reacting for $24 \mathrm{~h}$, DOXY $(54 \mathrm{mg})$ in anhydrous DMF was also added dropwise and reacted for another $24 \mathrm{~h}$. The unreacted DOX and DOXY were then removed by dialysis against dimethyl sulfoxide (DMSO) (MWCO: $1000 \mathrm{Da}$ ), and the resulting DOX-TK-DOXY was obtained by lyophilization.

Synthesis of BP/MSN/DOX-TK-DOXY. MSN-NH $\mathrm{N}_{2}$ was dissolved in deionized water, followed by the dropwise addition of DOX-TKDOXY under stirring for $24 \mathrm{~h}$. DMSO and EDC were then added and reacted for $6 \mathrm{~h}$, followed by the addition of ET, PA, AId, or ZA and reacted for another $24 \mathrm{~h}$. ET/MSN/DOX-TK-DOXY, PA/
MSN/DOX-TK-DOXY, AId/MSN/DOX-TK-DOXY, and ZA/ MSN/DOX-TK-DOXY were obtained via dialysis.

Preparation of Ce6-Adsorbed Formulations. Ce6@MSN/ DOX-TK-DOXY and Ce6@ZA/MSN/DOX-TK-DOXY (ZA; BP compound) were obtained by dialysis. In brief, MSN/DOX-TKDOXY or ZA/MSN/DOX-TK-DOXY (10 mg) and Ce6 (0.25, 0.5, $0.75,1,1.25,1.5,1.75,2.0,2.25,2.5$, or $3.0 \mathrm{mg}$ ) were dissolved in deionized water $(10.0 \mathrm{~mL})$ with stirring for $6 \mathrm{~h}$ in the dark. The mixtures were then transferred to a dialysis membrane (MWCO: $1000 \mathrm{Da})$ and dialyzed against ultrapure water overnight. To determine the loading capacity of $\mathrm{Ce} 6$, the amounts of $\mathrm{Ce} 6$ in the dialysates were measured by HPLC and subtracted from the total amounts of added Ce6. 
Stability. Ce6@ZA/MSN/DOX-TK-DOXY were incubated in PBS containing 10\% FBS or PBS alone. After incubation for 7 days, the diameters were measured everyday by DLS (Malvern, UK).

Bone Targeting. Fluorescein isothiocyanate (FITC) was dissolved in absolute ethyl alcohol. 3-(Aminopropyl)triethoxysilane (APTES) was then added, and the resulting mixture was stirred for 6 $\mathrm{h}$ to obtain FITC-APTES. Thereafter, $\mathrm{MSN}-\mathrm{NH}_{2}$ was dissolved in absolute ethyl alcohol and FITC-APTES was added under inverse flow for $24 \mathrm{~h}$ at $80{ }^{\circ} \mathrm{C}$. The mixture was then centrifuged at 13,000 $\mathrm{rpm}$ for $5 \mathrm{~min}$ and washed three times with absolute ethyl alcohol and deionized water to obtain FITC-ET/MSN, FITC-PA/MSN, FITC-AId/MSN, or FITC-ZA/MSN. The synthesis procedures for Ce6@ET/MSN/DOX-TK-DOXY, Ce6@PA/MSN/DOX-TKDOXY, and Ce6@AId/MSN/DOX-TK-DOXY were the same as those for Ce6@ZA/MSN/DOX-TK-DOXY.

Logarithmic OS-732 cells were seeded into 96-well plates $(200 \mu \mathrm{L}$ well $\left.{ }^{-1}\right)$ and cultured for $24 \mathrm{~h}$. Hydroxyapatite $\left(1 \mu \mathrm{g} \mathrm{mL}^{-1}\right)$ was then added and incubated for $2 \mathrm{~h}$. Subsequently, culture medium containing different concentrations of FITC-ET/MSN, FITC-PA/ MSN, FITC-AId/MSN, and FITC-ZA/MSN was added into the 96well plates $\left(200 \mu \mathrm{L}_{\text {well }}^{-1}\right)$ for $6 \mathrm{~h}$. After the $6 \mathrm{~h}$ incubation, the cells were washed twice with serum-free medium and observed by inverted fluorescence microscopy. The cell apoptosis and cell cycle procedures for Ce6@ET/MSN/DOX-TK-DOXY, Ce6@PA/MSN/ DOX-TK-DOXY, and Ce6@AId/MSN/DOX-TK-DOXY were the same as those for Ce6@ZA/MSN/DOX-TK-DOXY.

Characterization. ${ }^{1} \mathrm{H}$ NMR spectra were measured in deuterated $\mathrm{CDCl}_{3}$ and DMSO reagents using an AVANCE III 400-MHz NMR spectrometer (Bruker, Switzerland). The size and size stability of the samples were determined in a Zetasizer Nano size analyzer (Marvin Instruments Co. Ltd., England). The morphology of the samples was observed by a JEM-1400 transmission electron microscope (JEM, Japan) at an accelerating voltage of $120 \mathrm{kV}$. The absorption spectra of DOX, DOXY, and Ce6 were measured by a UV-2600 spectrophotometer (Shimadzu Corporation, Japan). The fluorescence intensity of DOX was measured by flow cytometry (BD FACSCanto $\mathrm{H}$; BD Biosciences, USA). The absorbance of DOXY was detected by a UV-2600 spectrophotometer (Shimadzu Corporation, Japan).

In Vitro DOX and DOXY Release. The releases of DOX and DOXY from Ce6@MSN/DOX-TK-DOXY, Ce6@ZA/MSN/DOXTK-DOXY, Ce6 + MSN/DOX-TK-DOXY, and Ce6 + ZA/MSN/ DOX-TK-DOXY were investigated by dialysis (MWCO: $1000 \mathrm{Da}$ ) at room temperature. During $0.5-72 \mathrm{~h}$, each solution was transferred into an EP tube, incubated in a water bath at room temperature, irradiated with a $660 \mathrm{~nm}$ laser at $0.1 \mathrm{~W} \mathrm{~cm}^{-2}$ for $20 \mathrm{~min}^{35}$ and transferred back to the dialysis membrane bag. At fixed intervals, the collected solutions of DOX and DOXY were measured by HPLC to determine their concentration.

Degradation of the $T K$ Linkage under $660 \mathrm{~nm}$ Laser Irradiation. Ce6@ZA/MSN/DOX-TK-DOXY were suspended in deionized water with $\mathrm{Ce} 6$ concentration of $0.125 \mu \mathrm{g} \mathrm{mL} \mathrm{m}^{-1}$ and subjected to $660 \mathrm{~nm}$ laser irradiation at $0.1 \mathrm{~W} \mathrm{~cm}^{-2}$. The resultant thiol groups were measured during degradation periods of $10,20,30$, 40, 50, and $60 \mathrm{~min}$.

In Vitro ROS Production. Ce6@ZA/MSN/DOX-TK-DOXY $\left([\mathrm{DOX}]=1.25 \mu \mathrm{g} \mathrm{mL}^{-1}\right.$; [DOXY $]=0.625 \mu \mathrm{g} \mathrm{mL}^{-1}$; [Ce6] $=0.125$ $\mu \mathrm{g} \mathrm{mL}{ }^{-1}$ ) were mixed with 9,10 anthracenediyl-bis (methylene) dimalonic acid in deionized water and subjected to $660 \mathrm{~nm}$ laser irradiation $^{42-44}$ at $0.1 \mathrm{~W} \mathrm{~cm}^{-2}$ for $10,20,30,40,50$, and $60 \mathrm{~min}$.

Cell Growth Inhibition Rate. The cells were seeded into 96-well plates $\left(200 \mu \mathrm{L}\right.$ well $\left.{ }^{-1}\right)$, and cultured for $24 \mathrm{~h}$. Culture medium containing different concentrations of Ce6 $(0,0.025,0.05,0.1,0.125$, 0.25, 0.5, or $1.0 \mu \mathrm{g} \mathrm{mL}^{-1}$ ) and Ce6@MSN/DOX-TK-DOXY, Ce6@ ZA/MSN/DOX-TK-DOXY, Ce6 + MSN/DOX-TK-DOXY, or Ce6 + ZAMSN/DOX-TK-DOXY $([\mathrm{Ce} 6]=0,0.025,0.05,0.1,0.125$, $0.25,0.5$, or $1 \mu \mathrm{g} \mathrm{mL}^{-1}$; $[\mathrm{DOX}]=0,0.5,0.75,1,1.25,1.5,1.75$, or 2 $\mu \mathrm{g} \mathrm{mL}^{-1}$; $[\mathrm{DOXY}]=0,0.25,0.375,0.5,0.625,0.75,0.875$, or $1 \mu \mathrm{g}$ $\left.\mathrm{mL}^{-1}\right)$ were added into the 96 -well plates $\left(200 \mu \mathrm{L}\right.$ well $\left.{ }^{-1}\right)$ for $6 \mathrm{~h}$. The laser was irradiated at $0.1 \mathrm{~W} \mathrm{~cm}^{-2}$ and MTT $(200 \mu \mathrm{L} ; 5 \mathrm{mg}$ $\mathrm{mL}^{-1}$ ) was added to each well after $20 \mathrm{~min}$ of laser irradiation. The plates were then centrifuged for $4 \mathrm{~h}$. After addition of DMSO (100 $\mu \mathrm{L}$ ) to each well, the absorbances of the wells were measured by a platereader. The cell growth inhibition rate (\%) was calculated using the equation shown below.

$$
\begin{aligned}
& \text { cell inhibition rate }(\%) \\
& =\left(\text { control group }_{\mathrm{OD}}-\text { experimental group }_{\mathrm{OD}}\right) \\
& \quad /\left(\text { control group }_{\mathrm{OD}}-\text { blank group }_{\mathrm{OD}}\right) \times 100 \%
\end{aligned}
$$

Generation of Intracellular ROS by Irradiation. Logarithmic OS-732 cells were seeded into 96-well plates $\left(200 \mu \mathrm{L} \mathrm{well}^{-1}\right)$ and cultured (with hydroxyapatite) for $24 \mathrm{~h}$. Culture medium containing different concentrations of DOX, DOXY, DOX + DOXY, Ce6, Ce6@MSN/DOX-TK-DOXY, Ce6@ZA/MSN/DOX-TK-DOXY, Ce6 + MSN/DOX-TK-DOXY, or Ce6 + ZAMSN/DOX-TK$\operatorname{DOXY}\left([\mathrm{Ce} 6]=0.125 \mu \mathrm{g} \mathrm{mL} \mathrm{m}^{-1} ;[\mathrm{DOX}]=1.25 \mu \mathrm{g} \mathrm{mL} \mathrm{m}^{-1}\right.$; $\left.[\mathrm{DOXY}]=0.625 \mu \mathrm{g} \mathrm{mL}^{-1}\right)$ were added into the 96-well plates $(200$ $\mu \mathrm{L}$ well $^{-1}$ ), followed by $660 \mathrm{~nm}$ laser irradiation at $0.1 \mathrm{~W} \mathrm{~cm}^{-2}$ for $20 \mathrm{~min}$ and further incubation for $6 \mathrm{~h}$. DCFH-DA was then added to all groups except the positive control group and incubated for another $2 \mathrm{~h}$. Subsequently, the cells were washed twice with serumfree medium, and evaluated by confocal microscopy and flow cytometry.

Viability Analysis of Living and Dead OS-732 Cells. Logarithmic OS-732 cells were seeded (with hydroxyapatite) into 96-well plates $\left(200 \mu \mathrm{L}\right.$ well $\left.^{-1}\right)$ and cultured for $24 \mathrm{~h}$. Culture medium containing different concentrations of Ce6, Ce6@MSN/ DOX-TK-DOXY, Ce6@ZA/MSN/DOX-TK-DOXY, Ce6 + MSN/ DOX-TK-DOXY, or Ce6 + ZAMSN/DOX-TK-DOXY $([\mathrm{Ce} 6]=$ $0.125 \mu \mathrm{g} \mathrm{mL}^{-1}$; [DOX] $=1.25 \mu \mathrm{g} \mathrm{mL}^{-1}$; [DOXY $]=0.625 \mu \mathrm{g} \mathrm{mL}^{-1}$ ) were added into the 96 -well plates $\left(200 \mu \mathrm{L} \mathrm{well}^{-1}\right)$, followed by 660 $\mathrm{nm}$ laser irradiation at $0.1 \mathrm{~W} \mathrm{~cm}^{-2}$ for $20 \mathrm{~min}$ and incubation for $6 \mathrm{~h}$. Subsequently, the cells were washed twice with serum-free medium and observed by inverted fluorescence microscopy.

Intracellular DOX and DOXY Release by Irradiation. OS-732 cells $\left(3 \times 10^{6}\right.$ cells well $\left.^{-1}\right)$ were incubated (with hydroxyapatite) at room temperature for $24 \mathrm{~h}$. Fresh culture medium containing Ce6@ MSN/DOX-TK-DOXY, Ce6@ZA/MSN/DOX-TK-DOXY, Ce6 + MSN/DOX-TK-DOXY, or Ce6 + ZA/MSN/DOX-TK-DOXY $\left([\mathrm{DOX}]=1.25 \mu \mathrm{g} \mathrm{mL}^{-1} ;[\mathrm{DOXY}]=0.625 \mu \mathrm{g} \mathrm{mL} \mathrm{g}^{-1} ;[\mathrm{Ce} 6]=\right.$ $0.125 \mu \mathrm{g} \mathrm{mL}^{-1}$ ) were added to replace the original medium. After incubation for $6 \mathrm{~h}$, the cells were washed twice with PBS and exposed to $660 \mathrm{~nm}$ laser irradiation at $0.1 \mathrm{~W} \mathrm{~cm}^{-2}$ for $20 \mathrm{~min}$. OS732 cells incubated with Ce6@MSN/DOX-TK-DOXY, Ce6@ZA/ MSN/DOX-TK-DOXY, Ce6 + MSN/DOX-TK-DOXY, or Ce6 + $\mathrm{ZA} / \mathrm{MSN} / \mathrm{DOX}-T K$-DOXY without irradiation were evaluated as control groups. After incubation for another $6 \mathrm{~h}$, the cells were washed twice, trypsinized, and resuspended in PBS. The qualitative and quantitative analyses of DOX and DOXY were measured by HPLC, ultraviolet spectrophotometry, and flow cytometry (BD FACSCanto H; BD Biosciences, USA).

For confocal microscopy observation, OS-732 cells were incubated (with hydroxyapatite) in 24-well plates $\left(3 \times 10^{6}\right.$ cells well $\left.^{-1}\right)$ at room temperature for $24 \mathrm{~h}$, and the medium was replaced with fresh culture medium containing Ce6@MSN/DOX-TK-DOXY or Ce6@ ZAMSN/DOX-TK-DOXY $\left([\mathrm{DOX}]=1.25 \mu \mathrm{g} \mathrm{mL}^{-1}\right.$; [DOXY $]=$ $0.625 \mu \mathrm{g} \mathrm{mL}^{-1}$; [Ce6] $\left.=0.125 \mu \mathrm{g} \mathrm{mL}^{-1}\right)$. After incubation for $4 \mathrm{~h}$ at $37^{\circ} \mathrm{C}$, the cells were washed twice with PBS and exposed to $660 \mathrm{~nm}$ laser irradiation at $0.1 \mathrm{~W} \mathrm{~cm}^{-2}$ for $20 \mathrm{~min}$. The cells were then incubated for $6 \mathrm{~h}$, washed with PBS, and fixed with $4 \%$ formaldehyde at $37{ }^{\circ} \mathrm{C}$ for $20 \mathrm{~min}$. Thereafter, the cell nuclei and cytomembranes were counterstained with DAPI and Alexa Fluor 488 phalloidin for confocal microscopy analysis (LSM 880 with Airyscam; Zeiss, Germany).

Cell Metabolism. Logarithmic OS-732 cells were seeded (with hydroxyapatite) into 96-well plates $\left(200 \mu \mathrm{L}_{\text {well }}{ }^{-1}\right)$ and cultured for 24 h. Culture medium containing Ce6@ZA/MSN/DOX-TK-DOXY $\left([\mathrm{Ce} 6]=0.125 \mu \mathrm{g} \mathrm{mL}^{-1}\right.$; [DOX] $=1.25 \mu \mathrm{g} \mathrm{mL}^{-1}$; $[\mathrm{DOXY}]=0.625$ $\left.\mu \mathrm{g} \mathrm{mL}^{-1}\right)$ was added to the 96 -well plates $\left(200 \mu \mathrm{L}\right.$ well $\left.{ }^{-1}\right)$, followed 
by $660 \mathrm{~nm}$ laser irradiation at $0.1 \mathrm{~W} \mathrm{~cm}^{-2}$ for $20 \mathrm{~min}$ and incubation for $6 \mathrm{~h}$. Subsequently, the cells were washed twice with serum-free medium and measured by ${ }^{1} \mathrm{H}$ NMR spectroscopy.

Cell Apoptosis, Cell Cycle, and MTP Assays. The cells (with hydroxyapatite) were treated with Ce6@ZA/MSN/DOX-TK-DOXY $\left([\mathrm{DOX}]=1.25 \mu \mathrm{g} \mathrm{mL}^{-1}\right.$; $[\mathrm{DOXY}]=0.625 \mu \mathrm{g} \mathrm{mL}^{-1}$; [Ce6] $=0.125$ $\left.\mu \mathrm{g} \mathrm{mL}^{-1}\right)$, subjected to $660 \mathrm{~nm}$ laser irradiation at $0.1 \mathrm{~W} \mathrm{~cm}^{-2}$ for 20 min, and incubated for $24 \mathrm{~h}$. Cell apoptosis, cell cycle, and MTP assays were performed by flow cytometry (BD FACSCanto $\mathrm{H}$; BD Biosciences, USA).

Serum DOX and DOXY Concentration. BALB/c mice (weight: 20-30 g) were administered a dose of Ce6@ZA/MSN/DOX-TK$\operatorname{DOXY}\left([\mathrm{DOX}]=5 \mathrm{mg} \mathrm{kg}^{-1}\right.$; [DOXY] $=2.5 \mathrm{mg} \mathrm{kg}^{-1}$; [Ce6] $=0.5$ $\left.\mathrm{mg} \mathrm{kg}^{-1}\right)$ by vein injection. Blood samples $(\sim 0.2 \mathrm{~mL})$ were extracted at fixed time intervals and subjected to centrifugation $(12,000 \mathrm{~g}$ for 20 min at $4{ }^{\circ} \mathrm{C}$ ). The concentrations of DOX and DOXY in the blood samples were determined by HPLC.

Animal and Tumor Models. BALB/c female mice (weight: 20$30 \mathrm{~g}$ ) were obtained from Southern Medical University (China). The procedures and care of the mice were authorized by the Institutional Ethics Committee of Southern Medical University (China). The experiments conformed to the Guide for the Care and Use of Laboratory Animals published by the US National Institutes of Health (NIH Publication updated in 2011). OS-732 cells $\left(3 \times 10^{7}\right)$ were injected into the distal bone marrow cavity of the femurs to establish an osteosarcoma model. When the tumor volumes reached $0.08 \mathrm{~cm}^{3}$, the mice were used for subsequent experiments.

In Vivo Fluorescence and MR Imaging. After intravenous injection of Ce6@ZA/MSN/DOX-TK-DOXY ([DOX ] = 5.0 mg $\mathrm{kg}^{-1} ;[\mathrm{DOXY}]=2.5 \mathrm{mg} \mathrm{kg}^{-1}$; $\left.[\mathrm{Ce} 6]=0.5 \mathrm{mg} \mathrm{kg}^{-1}\right)$, the in vivo fluorescence distribution in tumor-bearing mice was measured at fixed times using a multimode small-animal imaging system in vivo (FX Pro; Bruker, USA). At $24 \mathrm{~h}$ post-injection, the mice were sacrificed, and their solid tumor, kidney, spleen, liver, lung, and heart tissues were collected, washed with PBS, and imaged with the same multimode small-animal imaging system.

For in vivo MR imaging of tumors, Ce6-Gd@ZA/MSN/DOX-TK$\operatorname{DOXY}\left([\mathrm{DOX}]=5.0 \mathrm{mg} \mathrm{kg}^{-1} ;[\mathrm{DOXY}]=2.5 \mathrm{mg} \mathrm{kg}^{-1}\right.$; [Ce6] $=0.5$ $\mathrm{mg} \mathrm{kg}^{-1}$ ) were intravenously injected into the mice bearing OS-732 tumors. Subsequently, the tumor region in the mice was measured using a small-animal MR imaging system (Bruker BioSpin MRI GmbH, Pharma Scan70/16 US, USA). The imaging intensity of the tumors was analyzed at fixed times.

In Vivo Antitumor Efficacy. Mice bearing OS-732 tumors were randomly divided into 11 groups $(n=5)$ and intravenously injected with Ce6@MSN/DOX-TK-DOXY, Ce6@ZA/MSN/DOX-TKDOXY, Ce6 + MSN/DOX-TK-DOXY, Ce6 + ZA/MSN/DOX-TKDOXY, DOX, DOXY, DOX + DOXY, or Ce6 at DOX, DOXY, and Ce6 dosages of $5.0,2.5$, and $0.5 \mathrm{mg} \mathrm{kg}^{-1}$, respectively. At $24 \mathrm{~h}$ postadministration, the tumor site was subjected to $660 \mathrm{~nm}$ laser irradiation at $0.1 \mathrm{~W} \mathrm{~cm}^{-2}$ for $30 \mathrm{~min}$. Mice without irradiation were evaluated as controls. The mice received treatments every 4 days. The size and volume of the tumors were checked, and the mice were sacrificed to collect solid tumor tissues after 16 days.

HE Staining Assessment. Tumor, kidney, liver, spleen, lung, heart, and bone tissues were extracted and subjected to HE staining to evaluate the pathological injury.

Serum Alkaline Phosphatase Measurement. Blood was extracted from the abdominal aorta every 4 days and centrifuged to obtain the supernatant. Subsequently, serum alkaline phosphatase was measured using a kit method.

Qualitative and Quantitative Measurement of ROS. Solid tumor tissues were extracted every 4 days and shredded to obtain homogenates that were centrifuged to obtain supernatants. ROS were qualitatively and quantitatively determined using kit methods.

CD31 Expression Evaluation. Solid tumor vessels were extracted and shredded to obtain homogenates that were centrifuged to obtain supernatants. CD31 expression was determined by RTPCR (CD31 primers: 5'-GCCTTGGTAGAGCACA-3' and 5'GCCTTGGCTTTCCTCA-3').
Immunohistochemical Analysis. Tumor tissues and vessels were excised from sacrificed mice and fixed in $4 \%$ formaldehyde for immunohistochemical staining evaluation.

Statistical Analysis. The statistical significance of differences in data for the therapeutic groups was assessed by ANOVA and post hoc analysis of the ADRENAL Trial. analysis. Values of $P<0.05$ and $P<0.01$ were considered to indicate statistical significance in all analyses.

\section{ASSOCIATED CONTENT}

\section{Supporting Information}

The Supporting Information is available free of charge at https://pubs.acs.org/doi/10.1021/acsami.0c08992.

1H NMR spectra of TK, DOX-TK, and DOX-TKDOXY; inverted fluorescence microscopy images and cell apoptosis with TUNEL staining and cell cycle analyses of OS-732 cells; loading contents of Ce6 for Ce6@ZA/MSN/DOX-TK-DOXY; particle size, UV-vis absorption spectra, and DOX and DOXY release profiles of Ce6@ZA/MSN/DOX-TK-DOXY; phototriggered intracellular DOX and DOXY release; intracellular ROS production in OS-732 cells; cell apoptosis with TUNEL staining of OS-732 cells treated with Ce6@ZA/MSN/DOX-TK-DOXY; MTP measurements for Ce6@ZA/MSN/DOX-TK-DOX; OS-732 cell metabolism after different treatments; body weights of mice bearing OS-732 tumors; ROS analysis in tumor tissues after treatment with Ce6@ZA/MSN/DOX-TKDOXY; inner ring tumor microvessel tortuosity and density; HE staining of main organs after treatment; CD31 expression and RT-PCR analyses of tumor vessels; and quantification of DOX and DOXY contents in major organs (PDF)

\section{AUTHOR INFORMATION}

\section{Corresponding Authors}

Shuwen Liu - School of Pharmaceutical Sciences, Guangdong Provincial Key Laboratory of New Drug Screening, Southern Medical University, Guangzhou 510515, China; o orcid.org/ 0000-0001-6346-5006; Email: liusw@smu.edu.cn

Fei Peng - School of Materials Science and Engineering, Sun Yat-Sen University, Guangzhou 510275, China; Email: pengf26@mail.sysu.edu.cn

Yingfeng Tu - School of Pharmaceutical Sciences, Guangdong Provincial Key Laboratory of New Drug Screening, Southern Medical University, Guangzhou 510515, China; $\odot$ orcid.org/ 0000-0003-2605-0172; Email: tuyingfeng1@smu.edu.cn

\section{Authors}

Fei Tong - School of Pharmaceutical Sciences, Guangdong Provincial Key Laboratory of New Drug Screening, Southern Medical University, Guangzhou 510515, China

Yicheng Ye - School of Pharmaceutical Sciences, Guangdong Provincial Key Laboratory of New Drug Screening, Southern Medical University, Guangzhou 510515, China

Bin Chen - School of Pharmaceutical Sciences, Guangdong Provincial Key Laboratory of New Drug Screening, Southern Medical University, Guangzhou 510515, China

Junbin Gao - School of Pharmaceutical Sciences, Guangdong Provincial Key Laboratory of New Drug Screening, Southern Medical University, Guangzhou 510515, China 
Lu Liu - School of Pharmaceutical Sciences, Guangdong Provincial Key Laboratory of New Drug Screening, Southern Medical University, Guangzhou 510515, China

Juanfeng Ou - School of Pharmaceutical Sciences, Guangdong Provincial Key Laboratory of New Drug Screening, Southern Medical University, Guangzhou 510515, China

Jan C. M. van Hest - Institute for Complex Molecular Systems, Eindhoven University of Technology, Eindhoven 5600 MB, The Netherlands; ○ orcid.org/0000-0001-7973-2404

Complete contact information is available at: https://pubs.acs.org/10.1021/acsami.0c08992

\section{Notes}

The authors declare no competing financial interest.

\section{ACKNOWLEDGMENTS}

This work was supported by the National Natural Science Foundation of China (grant nos. 21805318, 51973241 and 31800835), Natural Science Foundation of Guangdong Province (2018B030306007 and 2018A030313521), Light Project of the West of the Chinese Academy of Sciences (2018XBQNXZB007). The authors thank the Pearl Youth Scholar Funded Scheme for support.

\section{REFERENCES}

(1) Battogtokh, G.; Gotov, O.; Kang, J. H.; Cho, J.; Jeong, T. H.; Chimed, G.; Ko, Y. T. Triphenylphosphine-Docetaxel ConjugateIncorporated Albumin Nanoparticles for Cancer Treatment. Nanomedicine 2018, 13, 325-338.

(2) Youn, Y. S.; Bae, Y. H. Perspectives on The Past, Present, and Future of Cancer Nanomedicine. Adv. Drug Delivery Rev. 2018, 130, $3-11$.

(3) Shi, J.; Kantoff, P. W.; Wooster, R.; Farokhzad, O. C. Cancer Nanomedicine: Progress, Challenges and Opportunities. Nat. Rev. Cancer 2017, 17, 20-37.

(4) Kansara, M.; Teng, M. W.; Smyth, M. J.; Thomas, D. M. Translational Biology of Osteosarcoma. Nat. Rev. Cancer 2014, 14, $722-735$.

(5) Chen, G.; Xie, Y.; Peltier, R.; Lei, H.; Wang, P.; Chen, J.; Hu, Y.; Wang, F.; Yao, X.; Sun, H. Peptide-Decorated Gold Nanoparticles As Functional Nano-Capping Agent of Mesoporous Silica Container for Targeting Drug Delivery. ACS Appl. Mater. Interfaces 2016, 8, 11204-11209.

(6) Dong, D.-W.; Xiang, B.; Gao, W.; Yang, Z.-Z.; Li, J.-Q.; Qi, X.R. pH-Responsive Complexes Using Prefunctionalized Polymers for Synchronous Delivery of Doxorubicin and Sirna to Cancer Cells. Biomaterials 2013, 34, 4849-4859.

(7) Ando, K.; Heymann, M.-F.; Stresing, V.; Mori, K.; Rédini, F.; Heymann, D. Current Therapeutic Strategies and Novel Approaches in Osteosarcoma. Cancers 2013, 5, 591-616.

(8) Taran, R.; Taran, S.; Malipatil, N. Pediatric Osteosarcoma: An Updated Review. Indian J. Med. Paediatr. Oncol. 2017, 38, 33-43.

(9) Bisht, S.; Maitra, A. Dextran-Doxorubicin/Chitosan Nanoparticles for Solid Tumor Therapy. Wiley Interdiscip. Rev.: Nanomed. Nanobiotechnol. 2009, 1, 415-425.

(10) Naz, S.; Wang, M.; Han, Y.; Hu, B.; Teng, L.; Zhou, J.; Zhang, H.; Chen, J. Enzyme Responsive Mesoporous Silica Nanoparticles for Tumor Cells and Mitochondria Multistage-Targeted Drug Delivery. Int. J. Nanomed. 2019, 14, 2533-2542.

(11) Shi, S.; Zhang, L.; Zhu, M.; Wan, G.; Li, C.; Zhang, J.; Wang, Y.; Wang, Y. Reactive Oxygen Species-Responsive Nanoparticles Based on Peglated Prodrug for Targeted Treatment of Oral Tongue Squamous Cell Carcinoma by Combining Photodynamic Therapy and Chemotherapy. ACS Appl. Mater. Interfaces 2018, 10, 2926029272.
(12) Fan, W.; Huang, P.; Chen, X. Overcoming The Achilles' Heel of Photodynamic Therapy. Chem. Soc. Rev. 2016, 45, 6488-6519.

(13) Fan, W.; Lu, N.; Xu, C.; Liu, Y.; Lin, J.; Wang, S.; Shen, Z.; Yang, Z.; Qu, J.; Wang, T.; Chen, S. Enhanced Afterglow Performance of Persistent Luminescence Implants for Efficient Repeatable Photodynamic Therapy. ACS Nano 2017, 11, 58645872.

(14) Dolmans, D.; Fukumura, D.; Jain, R. Photodynamic Therapy for Cancer. Nat. Rev. Cancer 2003, 3, 380-387.

(15) Lange, C.; Bednarski, P. Photosensitizers for Photodynamic Therapy: Photochemistry in The Service of Oncology. Curr. Pharm. Des. 2017, 22, 6956-6974.

(16) Dąbrowski, J.; Arnaut, L. Photodynamic Therapy (Pdt) of Cancer: from Local to Systemic Treatment. Photochem. Photobiol. Sci. 2015, 14, 1765-1780.

(17) Reginato, E.; Wolf, P.; Hamblin, M. Immune Response after Photodynamic Therapy Increases Anti-Cancer and Anti-Bacterial Effects. World J. Immunol. 2014, 4, 1-11.

(18) Wachowska, M.; Muchowicz, A.; Demkow, U. Immunological Aspects of Antitumor Photodynamic Therapy Outcome. Cent. Eur. J. Immunol. 2015, 4, 481-485.

(19) Perry, G.; Raina, A. K.; Nunomura, A.; Wataya, T.; Sayre, L. M.; Smith, M. A. How Important Is Oxidative Damage? Lessons from Alzheimer's Disease. Free Radical Biol. Med. 2000, 28, 831-834.

(20) Pelicano, H.; Carney, D.; Huang, P. ROS Stress in Cancer Cells and Therapeutic Implications. Drug Resist. Updates 2004, 7, 97-110.

(21) Spierings, D.; McStay, G.; Saleh, M.; Bender, C.; Chipuk, J.; Maurer, U.; Green, D. R. Connected to Death: The (Unexpurgated) Mitochondrial Pathway of Apoptosis. Science 2005, 310, 66-67.

(22) Tang, Z.; Liu, Y.; He, M.; Bu, X.-H. Chemodynamic Therapy: Tumour Microenvironment-Mediated Fenton and Fenton-like Reactions. Angew. Chem., Int. Ed. 2019, 58, 946-956.

(23) Allison, R. R.; Downie, G. H.; Cuenca, R.; Hu, X. H.; Childs, C. J.; Sibata, C. H. Photosensitizers in Clinical PDT. Photodiagn. Photodyn. Ther. 2004, 1, 27-42.

(24) Gao, L.; Zhang, C.; Gao, M.-T.; Liu, H.; Yu, X.; Lai, J.; Wang, F.; Lin, J.; Liu, Z. Enhanced Anti-Tumor Efficacy Through A Combination of Integrin $\alpha \mathrm{v} \beta 6$-Targeted Photodynamic Therapy and Immune Checkpoint Inhibition. Theranostics 2016, 6, 627-637.

(25) Mokwena, M. G.; Kruger, C. A.; Ivan, M.-T.; Heidi, A. A Review of Nanoparticle Photosensitizer Drug Delivery Uptake Systems for Photodynamic Treatment of Lung Cancer. Photodiagn. Photodyn. Ther. 2018, 22, 147-154.

(26) Mouratidis, P. X. E.; Colston, K. W.; Dalgleish, A. G. DOXY Induces Caspase-Dependent Apoptosis in Human Pancreatic Cancer Cells. Int. J. Cancer 2007, 120, 743-752.

(27) Duivenvoorden, W. C.; Hirte, H. W.; Singh, G. Use of Tetracycline as An Inhibitor of Matrix Metalloproteinase Activity Secreted by Human Bone-Metastasizing Cancer Cells. Invasion Metastasis 1997, 17, 312-322.

(28) Onoda, T.; Ono, T.; Dhar, D. K.; Yamanoi, A.; Fujii, T.; Nagasue, N. DOXY Inhibits Cell Proliferation and Invasive Potential: Combination Therapy with Cyclooxygenase-2 Inhibitor in Human Colorectal Cancer Cells. J. Lab. Clin. Med. 2004, 143, 207-216.

(29) Onoda, T.; Ono, T.; Dhar, D. K.; Yamanoi, A.; Nagasue, N. Tetracycline Analogues (DOXY and COL-3) Induce CaspaseDependent and Independent Apoptosis in Human Colon Cancer Cells. Int. J. Cancer 2006, 118, 1309-1315.

(30) Sannino, F.; Costantini, A.; Ruffo, F.; Aronne, A.; Venezia, V.; Califano, V. Covalent Immobilization of $\beta$-Glucosidase into Mesoporous Silica Nanoparticles from Anhydrous Acetone Enhances Its Catalytic Performance. Nanomaterials 2020, 10, 108.

(31) Sun, C.-Y.; Cao, Z.; Zhang, X.-J.; Sun, R.; Yu, C.-S.; Yang, X. Cascade-Amplifying Synergistic Effects of Chemo-Photodynamic Therapy Using Ros-Responsive Polymeric Nanocarriers. Theranostics 2018, 8, 2939-2953.

(32) Pei, P.; Sun, C.; Tao, W.; Li, J.; Yang, X.; Wang, J. ROSSensitive Thioketal-Linked Polyphosphoester-Doxorubicin Conjugate 
for Precise Phototriggered Locoregional Chemotherapy. Biomaterials

2019, 188, 74-82.

(33) Moser, M.; Behnke, T.; Hamers-Allin, C.; Klein-Hartwig, K.; Falkenhagen, J.; Resch-Genger, U. Quantification of Peg-Maleimide Ligands and Coupling Efficiencies on Nanoparticles with Ellman's Reagent. Anal. Chem. 2015, 87, 9376-9383.

(34) Phadungcharoen, N.; Patrojanasophon, P.; Opanasopit, P.; Ngawhirunpat, T.; Chinsriwongkul, A.; Rojanarata, T. SmartphoneBased Ellman's Colourimetric Methods for The Analysis of DPenicillamine Formulation and Thiolated Polymer. Int. J. Pharm.

2019, 558, 120-127.

(35) Cao, Z.; Ma, Y.; Sun, C.; Lu, Z.; Yao, Z.; Wang, J.; Li, D.; Yuan, Y.; Yang, X. ROS-Sensitive Polymeric Nanocarriers with Red Light-Activated Size Shrinkage for Remotely Controlled Drug Release. Chem. Mater. 2018, 30, 517-525.

(36) Bavelloni, A.; Focaccia, E.; Piazzi, M.; Errani, C.; Blalock, W.; Faenza, I. Cell Cycle Arrest and Apoptosis Induced by Kinamycin F in Human Osteosarcoma Cells. Anticancer Res. 2017, 37, 4103-4109.

(37) Li, Y.-Y.; Zhang, Z.; Wang, Z.-H.; Wang, H.-W.; Zhang, L.; Zhu, L. rBTI Induces Apoptosis in Human Solid Tumor Cell Lines by Loss in Mitochondrial Transmembrane Potential and Caspase Activation. Toxicol. Lett. 2009, 189, 166-175.

(38) Bhattacharyya, A.; Lahiry, L.; Mandal, D.; Sa, G.; Das, T. Black Tea Induces Tumor Cell Apoptosis by Bax Translocation, Loss in Mitochondrial Transmembrane Potential, Cytochrome C Release and Caspase Activation. Int. J. Cancer 2005, 117, 308-315.

(39) Fallah, M.; Mohammadi, H.; Shaki, F.; Hosseini-Khah, Z.; Moloudizargari, M.; Dashti, A.; Ziar, A.; Mohammadpour, A.; Mirshafa, A.; Modanloo, M.; Shokrzadeh, M. Doxorubicin and Liposomal Doxorubicin Induce Senescence by Enhancing Nuclear Factor Kappa B and Mitochondrial Membrane Potential. Life Sci. 2019, 232, 116677.

(40) Gong, H.; Dong, Z.; Liu, Y.; Yin, S.; Cheng, L.; Xi, W.; Xiang, J.; Liu, K.; Li, Y.; Liu, Z. Engineering of Multifunctional NanoMicelles for Combined Photothermal and Photodynamic Therapy under The Guidance of Multimodal Imaging. Adv. Funct. Mater. 2014, 24, 6492-6502.

(41) Darwish, K. M.; Salama, I.; Mostafa, S.; El-Sadek, M. RPHPLC/Pre-Column Derivatization for Analysis of Omeprazole, Tinidazole, Doxycycline and Clarithromycin. J. Chromatogr. Sci. 2013, 51, 566-576.

(42) Wu, R.; Wang, H.; Hai, L.; Wang, T.; Hou, M.; He, D.; He, X.; Wang, K. A photosensitizer-loaded zinc oxide-polydopamine coreshell nanotherapeutic agent for photodynamic and photothermal synergistic therapy of cancer cells. Chin. Chem. Lett. 2020, 31, 189192.

(43) An, H.; Guo, C.; Li, D.; Liu, R.; Xu, X.; Guo, J.; Ding, J.; Li, J.; Chen, W.; Zhang, J. Hydrogen Peroxide-Activatable Nanoparticles for Luminescence Imaging and in Situ Triggerable Photodynamic Therapy of Cancer. ACS Appl. Mater. Interfaces 2020, 12, 1723017243.

(44) Peng, H.; Qin, Y.-T.; He, X.-W.; Li, W.-Y.; Zhang, Y.-K. Epitope Molecularly Imprinted Polymer Nanoparticles for Chemo-/ Photodynamic Synergistic Cancer Therapy Guided by Targeted Fluorescence Imaging. ACS Appl. Mater. Interfaces 2020, 12, 1336013370. 